\title{
A sensitivity study on the effects of particle chemistry, asphericity and size on the mass extinction efficiency of mineral dust in the earth's atmosphere: from the near to thermal IR
}

\author{
R. A. Hansell Jr. ${ }^{1,3}$, J. S. Reid ${ }^{2}$, S. C. Tsay ${ }^{3}$, T. L. Roush $^{4}$, and O. V. Kalashnikova ${ }^{5}$ \\ ${ }^{1}$ University of Maryland, College Park, Maryland, USA \\ ${ }^{2}$ Naval Research Laboratory, Monterey, California, USA \\ ${ }^{3}$ Goddard Space Flight Center, NASA, Greenbelt, Maryland, USA \\ ${ }^{4}$ NASA Ames, Research Center, Moffett Field, California, USA \\ 5 Jet Propulsion Laboratory, California Institute of Technology, Pasadena, California, USA \\ Received: 14 May 2010 - Published in Atmos. Chem. Phys. Discuss.: 14 July 2010 \\ Revised: 14 December 2010 - Accepted: 30 January 2011 - Published: 17 February 2011
}

\begin{abstract}
To determine a plausible range of mass extinction efficiencies (MEE) of terrestrial atmospheric dust from the near to thermal IR, sensitivity analyses are performed over an extended range of dust microphysical and chemistry perturbations. The IR values are subsequently compared to those in the near-IR, to evaluate spectral relationships in their optical properties. Synthesized size distributions consistent with measurements, model particle size, while composition is defined by the refractive indices of minerals routinely observed in dust, including the widely used OPAC/Hess parameterization. Single-scattering properties of representative dust particle shapes are calculated using the T-matrix, Discrete Dipole Approximation and Lorenz-Mie light-scattering codes. For the parameterizations examined, MEE ranges from nearly zero to $1.2 \mathrm{~m}^{2} \mathrm{~g}^{-1}$, with the higher values associated with non-spheres composed of quartz and gypsum. At near-IR wavelengths, MEE for non-spheres generally exceeds those for spheres, while in the thermal IR, shape-induced changes in MEE strongly depend on volume median diameter (VMD) and wavelength, particularly for MEE evaluated at the mineral resonant frequencies. MEE spectral distributions appear to follow particle geometry and are evidence for shape dependency in the optical properties. It is also shown that nonspheres best reproduce the positions of prominent absorption peaks found in silicates. Generally, angular particles exhibit wider and more symmetric MEE spectral distribution patterns from 8-10 $\mu \mathrm{m}$ than those with smooth surfaces, likely due to their edge-effects. Lastly, MEE ratios allow for infer-
\end{abstract}

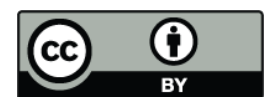

Correspondence to: R. A. Hansell Jr. (richard.a.hansell@nasa.gov) ring dust optical properties across the visible-IR spectrum. We conclude the MEE of dust aerosol are significant for the parameter space investigated, and are a key component for remote sensing applications and the study of direct aerosol radiative effects.

\section{Introduction}

In Earth's atmosphere, dust particles both scatter and absorb solar and terrestrial radiation, with the radiative interactions critically depending on the bulk optical and microphysical properties of the constituent minerals. Previous works have clearly demonstrated the inherent difficulties in modeling dust due to the large uncertainties in their physicochemical properties (e.g., Sokolik et al., 1999; J. S. Reid et al., 2003). More measurements of dust properties having greater spatial, temporal, and spectral coverage are absolutely essential, as these ultimately define the aerosol inputs used by radiative transfer and global climate models. The model inputs are represented by a set of wavelength dependent single-scattering parameters which are functions of the particle's mineral composition, geometric size, and morphology. These include the single-scattering albedo $(\varpi-$ the percentage of light extinction due to scattering), asymmetry parameter $(g-$ a parameterization that describes the particle phase function), and extinction coefficient ( $\beta_{\text {ext }}-$ the amount of scattering and absorption per unit path length).

Another parameter commonly employed in aerosol studies is the mass extinction efficiency (MEE) ( $\alpha_{\text {ext }}-$ Hand et al., 2007 and references therein) which defines the total light

Published by Copernicus Publications on behalf of the European Geosciences Union. 
extinction per unit mass of aerosol (Note, although the strict definition of aerosol includes the suspension medium, i.e. air, this study only refers to the particulate component). Also referred to as the specific extinction cross-section (Gerasopoulos et al., 2009), MEE is the sum of the mass scattering and mass absorption efficiencies (MSE and MAE, respectively). MEE is particularly useful for converting observed aerosol mass into an equivalent optical depth $(\tau)$ for computing direct aerosol radiative effects (DARE - units of $\mathrm{Wm}^{-2}$ ) essential to climate research (e.g., Myhre et al., 2001; Hansell et al., 2010). In previous works, this parameter has been determined experimentally using both field and laboratory measurements (e.g., Li et al., 1996; Maring et al., 2000 and Clarke et al., 2004) and through model calculations (e.g., Hand et al., 2002; Quinn et al., 2004 and Malm et al., 2005) at the visible wavelengths.

Prior research has demonstrated that MEE varies widely depending on particle type, the method employed and the conditions under which it is measured or calculated. Hand et al. (2007) for example, conducted an extensive survey of ground-based estimates of visible $(\lambda \sim 0.55 \mu \mathrm{m})$ MEE for various aerosol types and size modes using published literature since 1990. Hand et al. (2007) showed that MSE (a major component of MEE at visible wavelengths) for fine and coarse-mode dust, varied from $1.2 \pm 0.3$ to $0.9 \pm 0.8 \mathrm{~m}^{2} \mathrm{~g}^{-1}$ for theoretical and measurement methods, respectively.

Besides the reported variability in MEE at the visible wavelengths, there is limited or virtually no information on MEE in the near to thermal IR, which was the impetus for this study. In the IR, MEE is important for dust remote sensing studies. Potential applications include the retrieval of key land and atmospheric parameters (e.g., land and sea surface temperatures (LST/SST), water vapor and clouds) from satellite-based sensors such as the Moderate Resolution Imaging Spectroradiometer (MODIS - Levy et al., 2007), the Advanced Very High Resolution Radiometer (AVHRR - Arbelo et al., 2005), and the Atmospheric Infrared Sounder (AIRS - DeSouza-Machado et al., 2006). To demonstrate the utility of MEE in the IR, an example is given in section 4 related to dust's impact on SST retrievals. In the IR, MEE can also be used to better characterize the longwave (LW) radiative energetics of the atmosphere. This work represents to the best of our knowledge, the first time that MEE for dust aerosol has been quantified over such a broad range of parameters.

The underlying goal of this study is to use combined analytical and numerical light-scattering models to build a welldefined, spectrally resolved dataset of plausible dust MEE values, as a function of particle chemistry, asphericity, and size, at key remote sensing wavelengths that span the near-IR $(\lambda=0.87-3.75 \mu \mathrm{m})$ and thermal IR window $(\lambda=8-12 \mu \mathrm{m})$ regions. This work primarily focuses on dust properties that are considered extreme (e.g., single mineral compositions with strong absorption and having large particle sizes and aspect ratios) in order to construct a full spectral envelope of MEE and to help identify its upper and lower bounds. For reference, dust properties from previous laboratory and field studies are used to assess where likely values might fall within the spectral envelope. Moreover, comparisons of dust MEE are made between the visible and IR wavelengths to help bridge their optical properties. Supplemental datasets of MEE/MAE for several key minerals (e.g., quartz) are available online. For access to the full MEE/MAE mineral datasets, please contact the authors.

Invariably, there are uncertainties in the model studies of light scattering, due in part to limitations in the numerical schemes employed and assumptions made for characterizing particle properties (Nousiainen et al., 2009a). Although an exact dust model is still far too complex to simulate (i.e., one that fully accounts for surface roughness/porosity, mineral partitioning, orientation, etc.), simplifications are made to best represent airborne dust particles employing common microphysical and chemistry parameterizations. Because the number of global dust properties is so large and varied, we limit our analyses to the following:

1. Only MEE and the component MSE and MAE of pure dust minerals are examined, excluding the possibilities of coatings or aggregates with other aerosols (e.g., soot, sulfates, etc.), as in the case of aged or transported dust. Characterizing uncontaminated dust aerosol over this spectral domain is essential before investigating more complex mixtures and coatings; however, for illustrative purposes, a simple dust-soot mixture is presented.

2. The MEE is computed for common remote sensing wavelengths between $\lambda=0.870-12 \mu \mathrm{m}$.

3. The MEE of single mineral dust particles are evaluated mainly to address extreme cases in particle composition, that is, the full envelope of possible values is determined.

4. To address mineral compositions typically used in contemporary research, the Hess/OPAC dust parameterization, and a two-component dust mixture consisting of silicate-hematite are evaluated. Dust MEE using mineralogical results from SAMUM 2006 are also presented.

5. Size distributions have volume median diameters (VMD) in the range of $1.6-20 \mu \mathrm{m}$, with a baseline geometric standard deviation $\left(\sigma_{\mathrm{g}}\right)$ of 2 , which is later tested with a range in $\sigma_{\mathrm{g}}$ from 1.7-2.3.

6. Irregular dust shapes are represented by common polyhedral geometries.

7. Although single dust shape distributions are mainly used, two possible shape scenarios are investigated: background dust and dust storm. 
Potential benefits of this study include (1) promoting further insight into the LW contributions of dust DARE, (2) allowing for improved retrievals of SST and other surface parameters, and water vapor, (3) providing a reference by which field derived MEE data (e.g., from bulk mass and light scattering measurements) can be compared to, thus allowing for some improved measure of data interpretation, and (4) providing constraints for dust modeling studies

The paper is arranged as follows: the dust chemistry and microphysical parameterizations pertinent to this study are presented in Sect. 2; an overview of the theory and numerical scheme used to compute dust MEE is detailed in Sect. 3; the computational results, their implications and examples of potential applications are presented in Sect. 4, and finally a summary is given in Sect. 5 .

\section{Physicochemical properties of mineral dust}

\subsection{Mineralogy}

Interactions of LW radiation with airborne minerals primarily occur due to the fundamental vibrational modes of the component dust molecules, where the number, intensity, and shape of the modes are dependent on the atomic masses, interatomic force fields, and molecular geometry (Salisbury et al., 1991). The optical constants of many common dust minerals that describe these interactions are well documented (e.g., Roush et al., 2007; Glotch et al., 2007).

For this study, the following major mineral classes were selected to characterize dust particle composition: silicates, clays, carbonates, sulfates, and iron oxides. Although other mineral classes abound in nature, (e.g., phosphates, nonferrous oxides, sulfides, halides, etc.), literature surveys of dust chemistry from both laboratory and field measurements (e.g., Formenti et al., 2008; Chou et al., 2008; Kandler et al., 2009 and E. A. Reid et al., 2003) suggest these are the dominate classes. The refractive index datasets for the minerals employed in this study including their spectral ranges and reference sources are listed in Table 1. The minerals include: (1) quartz, muscovite, chlorite, and the clays kaolinite, montmorillonite, and illite, all from the silicate group, (2) calcite (i.e., calcium carbonate or limestone) and dolomite (calciummagnesium-carbonate) from the carbonate group, (3) the sulfate gypsum (hydrated-calcium-sulfate), and lastly, (4) the iron-oxide, hematite. The global significance of these minerals have been corroborated by numerous studies of dust samples from the Saharan desert during the SAMUM, PRIDE, SHADE, and AMMA field campaigns (Kandler et al., 2009; E. A. Reid et al., 2003; Formenti et al., 2003, 2008 and Chou et al., 2008, respectively), and Northern China (Arimoto et al., 2006 - ACE ASIA, Jeong et al., 2008), two of the world's largest dust sources. Examples of dust minerals found during past studies are shown in Table 2.
Prominent spectral features of these dust minerals are depicted in Fig. 1, where the imaginary component of the refractive index $(k)$, which is related to the absorption coefficient $\left(\alpha^{\prime}\right)$ via the dispersion relation:

$k=\alpha^{\prime} \lambda / 4 \pi$

is plotted as a function of wavelength $(\lambda)$ from $0.20-12.5 \mu \mathrm{m}$ (note, the wavelengths used in surface remote sensing applications are enclosed in light gray boxes for reference).

At $\lambda \leq 8 \mu \mathrm{m}$ for example, Fig. 1a shows several strong absorption bands including gypsum (red curve) likely attributed to combination tones of the sulfate ion and perhaps water $(\lambda \approx 2.8,4.6$, and $6 \mu \mathrm{m})$, and those due to the carbonate ion in calcite and also dolomite at $\lambda=7 \mu \mathrm{m}$ (green and blue curves, respectively - both scaled down $5 \times$ ). Weak absorbers are shown in Fig. 1b over the same spectral range.

Arguably, the most commonly observed spectral features can be found in the silicates, the largest mineral group, across the thermal IR window region. Here the phyllosilicate (e.g., clays and micas) and tectosilicate (e.g., quartz and feldspars) minerals compose much of the observed fraction of airborne dust. For example, the fundamental asymmetric stretching vibrations of the $\mathrm{Si}-\mathrm{O}$ bonds $\left(v_{2}\right)$ give rise to the classic absorption feature of quartz centered at $9.2 \mu \mathrm{m}$ (dashed blue curve - Fig. 1c). Gypsum (red curve) centered at $8.7 \mu \mathrm{m}$ is also dominant but varies with spectral position, strength, and shape. Lastly, Fig. 1d illustrates the complex spectral features associated with common clay minerals and the mica, muscovite. Although wavenumbers $\left(v-\right.$ in $\left.\mathrm{cm}^{-1}\right)$ are typically employed in IR studies, we continue to use units of wavelength $(\lambda-$ in $\mu \mathrm{m})$.

To elucidate the effects of strong absorption (i.e., particles with extreme refractive indices) on MEE, we mainly focus on single mineral dust particles. This is important, since large absorption features of individual minerals tend to average out in heterogeneous dust mixtures. Dust MAE is later examined in this study to help explain these strongly absorbing regions. The significance of evaluating the light scattering properties of individual minerals was also recently pointed out by Nousiainen et al. (2009b).

To illustrate the effects of more complex dust mineralogies on MEE, and those more typically observed during measurements, we employ (1) the frequently used Hess/OPAC dust parameterization (Hess et al., 1998) for transported dust, (2) a two component internal dust mixture composed of silicates (quartz, kaolinite, montmorillonite) and hematite, (3) an averaged weighted mixture of minerals representative of those observed during SAMUM 2006 (Kandler et al., 2009), and (4) a weighted dust-soot mixture using volume fraction soot amounts from Müller et al. (2009) to estimate potential anthropogenic contributions to dust MEE.

The Hess/OPAC parameterization consists of a mixture of quartz and clay minerals (see D'Almeida et al., 1991; Shettle and Fenn, 1979 and Koepke et al., 1997) and represents mobilized dust from source regions like the Saharan or Gobi 
Table 1. Refractive index datasets of common dust minerals

\begin{tabular}{lrl}
\hline Mineral & Wavelength $(\mu \mathrm{m})$ & Reference source \\
\hline Quartz & $0.2-300$ & Gray (1963), Drummond (1935); Spitzer and Kleinman (1961); Philipp (1985); Longtin et al. (1988) \\
Hematite & $0.2-300$ & Longtin et al. (1988) \\
Kaolinite & $0.185-2.6$ & Egan and Hilgeman (1979) \\
Kaolinite & $5-25$ & Roush et al. (1991) \\
Montmorillonite & $0.185-25$ & Roush (2005); Egan and Hilgeman (1979) \\
Illite & $0.185-2.6$ & Egan and Hilgeman (1979) \\
Illite & $2.5-200$ & Querry (1987) \\
Muscovite & $6.6-31$ & Aronson and Strong (1975) \\
Calcite & $2.5-333$ & Long et al. (1993) \\
Dolomite & $2.5-40$ & Querry (1987) \\
Gypsum & $0.4-333$ & Roush et al. (2007) \\
Chlorite & $2.5-50$ & Mooney and Knacke (1985) \\
\hline
\end{tabular}

Table 2. Minerals identified during past field studies.

\begin{tabular}{lll}
\hline Field study & Minerals reported & Notes \\
\hline PRIDE $^{1}$ & Gypsum/calcium carbonates (10\%) & E. A. Reid et al. (2003) found dust usually to be in the form of large, amor- \\
& Amorphous silicates (20\%) & phous alumino-silicate clay particles. \\
& Layered silicates (70\%) & Largest group was layered silicates (Al-Si clay particles/feldspars) such as \\
& & illite, kaolinite, and montmorillonite. \\
& Amorphous silicates are agglomerates of clay particles.
\end{tabular}

\begin{tabular}{|c|c|c|}
\hline Asian dust ${ }^{2}$ & $\begin{array}{l}\text { Illite }(19 \%) \\
\text { Interstratified illite-smectite }(22 \%) \\
\text { Chlorite }(2 \%) \\
\text { Smectite }(1 \%) \\
\text { Kaolinite }(1 \%) \\
\text { K-feldspar }(8 \%) \\
\text { Calcite }(8 \%) \\
\text { Plagioclase }(11 \%) \\
\text { Quartz }(28 \%)\end{array}$ & $\begin{array}{l}\text { Average mineral composition of bulk dust samples by X-ray diffraction } \\
\text { reported by Jeong (2008). } \\
\text { Most common minerals identified were clay aggregates. }\end{array}$ \\
\hline SAMUM $^{3}$ & $\begin{array}{l}\text { Hematite }(1 \%) \\
\text { Clays } \quad(15 \%) \quad \text { [illite + kaolinite + chlorite }] \\
\text { Feldspars }(14 \%) \quad \text { [K-feldspars + plagioclase }] \\
\text { Calcite }(3 \%)\end{array}$ & $\begin{array}{l}\text { Composition amounts estimated from Kandler et al. (2009) for dust storm } \\
\text { conditions with quartz being the dominate mineral } \\
\text { Kandler et al. (2009) used X-ray diffraction analysis followed by the RIR } \\
\text { method to identify and calculate relative mineral contents. }\end{array}$ \\
\hline
\end{tabular}

1 PRIDE 2000 - Transported Saharan dust E. A. Reid et al. (2003).

2 Asian dust - Dust samples from Korea and various source regions in China Jeong (2008).

3 SAMUM 2006 - Saharan dust near source region Kandler et al. (2009).

deserts, where many field measurements have been made (e.g., AMMA/NAMMA - Redelsperger et al., 2006; Zipser et al., 2009, SAMUM - Kandler et al., 2009 and ACE-ASIA - Arimoto et al., 2006).

The SAMUM 2006 dust mixture is based on the work of Kandler et al. (2009) (refer to Fig. 10) where average relative compositions of dust storm and low dust conditions were used to calculate MEE spectra. Plagioclase and K-feldspar mineral components were represented by anorthosite and andesite, respectively due to the availability of their optical data. MEE spectra for SAMUM 2006 are computed across the thermal IR window region only, since the refractive indices of the minerals calcite and chlorite are limited in the near-IR (Sect. 3.2). 
(a)

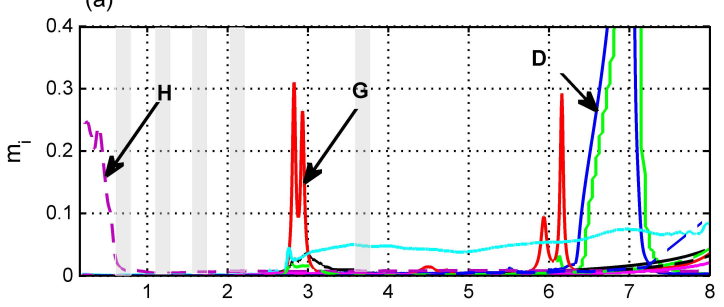

(c)

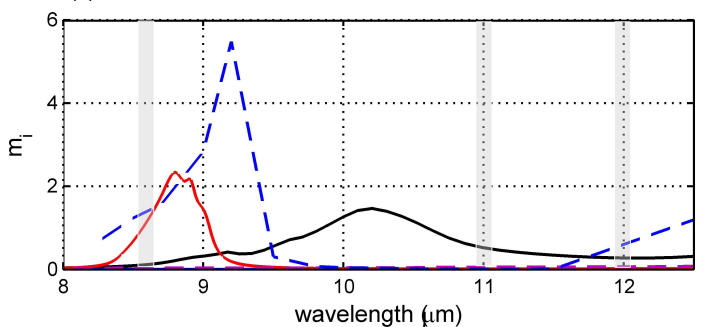

(b)

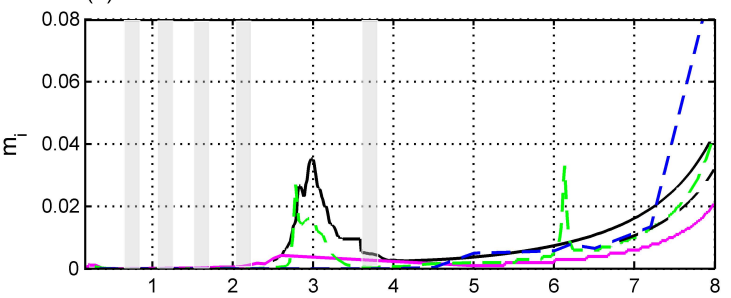

(d)

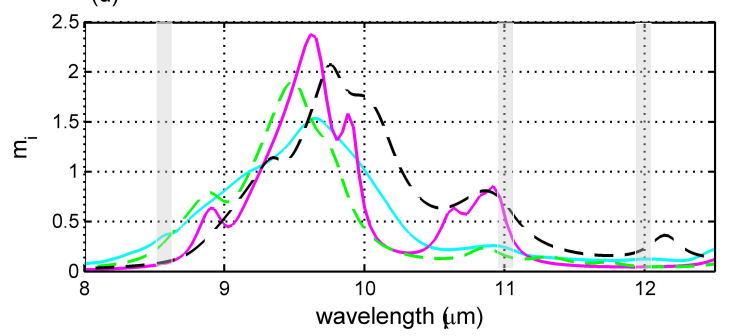

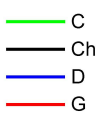

$--\mathrm{H}$

$-\mathrm{K}$

$--M$

$--\mathrm{Mu}$

$--Q$

Fig. 1. Imaginary component of refractive index for common dust minerals, with vertical axes re-scaled to resolve spectral features. Gray shaded regions represent common remote sensing channels. Shown are the minerals calcite (C), chlorite (Ch), dolomite (D), gypsum (G), hematite (H), illite (I), kaolinite (K), montmorillonite (M), muscovite (Mu) and quartz (Q). (a) strong absorbers for $\lambda \leq 8 \mu \mathrm{m}$ with $\mathrm{D}$ and $\mathrm{C}$ scaled down $5 \times$, (b) weak absorbers for $\lambda \leq 8 \mu \mathrm{m}$, (c) Q, G, Ch, and H in the window region, and (d) same as (c) except for the clays and Mu.

The weighted dust-soot mixture from Hess/OPAC was constructed based on the work of Müller et al. (2009) from SAMUM-1. Müller et al. (2009) show the volume fraction soot $(\%)$ for fine and dust modes to be $0.25,0.41,0.08$, and 0.28 for four time periods. For this study, the maximum fraction soot amount $(41 \%)$ is used.

Although recent estimates by Lafon et al. (2006), Formenti et al. (2008) and Lazaro et al. (2008) for example, report the iron oxide content in mineral dust should not exceed 5\%, we introduce a $10 \%$ hematite mixture for representing extreme cases of particle composition to help identify the bounds of the MEE spectral envelope. To help illustrate where in the envelope a typical measurement might fall, a $2 \%$ mixture is also computed. Clay-hematite mixtures are determined by applying the Maxwell-Garnett (MG) Rule (Note - although the MG rule cannot predict the influence of cationic substitutions within crystals, which can lead to changes in the positions of spectral features, this will not impact the results of this study). These mixtures may be representative of Saharan dust, where hematite is commonly found (Linke et al., 2006).

The significance of birefringence (i.e., a particle's variable dielectric properties along each of the crystallographic directions) on the scattering of calcite flakes has been recently reported by Nousiainen et al. (2009b). To account for a mineral's birefringent properties, we follow the work of Long et al. (1993) and compute an average of the refractive indices over each crystallographic direction, assuming randomly oriented particles. This procedure was performed for quartz, calcite, muscovite, hematite, and dolomite.

\subsection{Particle size}

Dust particle size is usually characterized as being lognormally distributed (Seinfeld, 1998; D'Almeida et al., 1991) either in terms of its particle number concentration $[d N / d \log 10(r)]$, surface area $[d A / d \log 10(r)]$ or volume $[d V / d \log 10(r)]$. In many cases, particle sizes are distributed over several size modes, depending on such factors as geographic location, the age of the dust plume and the interactions of dust with other aerosols. The partitioning of size modes may be due to contributions from either fine or coarse mode dust particles, i.e., those with effective radii $\left(r_{\text {eff }}\right)$ less than or greater than $0.4 \mu \mathrm{m}$, respectively (J. S. Reid et al., 2003, 2008). To assess the impact of extreme size parameters on MEE, coarse-mode normalized volume size distributions based on the lognormal expression:

$$
\begin{aligned}
n_{N}\left(D_{\mathrm{p}}\right)= & N\left((2 \pi)^{1 / 2} \ln \left(\sigma_{g}\right) D_{\mathrm{p}}\right)^{-1} \exp \\
& {\left[-\ln \left(D_{\mathrm{p}} / r_{g}\right)^{2} / 2 \ln \left(\sigma_{g}\right)^{2}\right] }
\end{aligned}
$$

are constructed, where $N$ is the particle number concentration (held constant in the number to volume transition) and $r_{\mathrm{g}}$ and $\sigma_{\mathrm{g}}$ are the radius and standard deviation of the monomodal distribution, respectively. The size distributions are consistent with measurements from past field campaigns; For example, PRIDE and $\mathrm{UAE}^{2}$ (J. S. Reid et al., 2003, 2008, respectively), SAMUM (Kahn et al., 2009 and Schladitz et al., 2009), and AMMA (Redelsperger et al., 2006), where Haywood et al. (2008) reported on results from AMMA/SOP0-DABEX and Zipser et al. (2009), focused on the NASA extension of AMMA (NAMMA) at the Cape Verde Islands. 
Following the work of J. S. Reid et al. (2003, 2008), we use the volume median diameter (VMD) as our size metric for dust. The computed VMD for this study include: 1.6, 3.0, 6.0, 9.0, 12.0, 18, and $20 \mu \mathrm{m}$ (where $N$ is held constant in the variation of VMD), although most observations place the VMD of coarse-mode dust in the 1.5-9 $\mu \mathrm{m}$ range with a majority of reported values between 3-6 $\mu \mathrm{m}$ (J. S. Reid et al., 2003, 2008). As a note, during SAMUM 2006, Weinzierl et al. (2009) reported averaged VMD values of $15.5 \pm 10.9 \mu \mathrm{m}$, where giant sized particles $(20-40 \mu \mathrm{m})$ were found about $70 \%$ of the time. Direct comparisons of particle sizes in literature, however, must be exercised with caution due to the differences in measurement techniques (J. S. Reid et al., 2003). All volume size distributions are then converted to mass spectra by multiplying the volume with the appropriate mass density (rho) of each mineral (Table 3). Consistent with prior observations of dust particle size (J. S. Reid et al., 2003), a baseline $\sigma_{\mathrm{g}}$ of 2.0 is employed for all calculations which we later adjust to test its effect on MEE.

\subsection{Particle morphology}

Dust particles are rarely spherical as evidenced from numerous prior works (e.g., Kandler et al., 2009; Otto et al., 2009; Kalashnikova et al., 2002, 2004, E. A. Reid et al., 2003 and Okada et al., 2001). Moreover, natural dust particles are found to be angular and jagged, likely due to preferential breakage along natural cleavage planes, the tendency of clay minerals to flake, and the dust particle's propensity to form aggregates, i.e., clusters of internally mixed minerals.

This study investigates the effect that particle asphericity has on dust MEE by employing a diverse but representative collection of dust particle morphologies, ranging from various axisymmetric geometries to those that are highly irregular. These dust shapes are based on observed microphysical parameters from field studies (e.g., Kandler et al., 2009; Müller et al., 2010; Chou et al., 2008; E. A. Reid et al., 2003 and Okada et al., 2001), shape information from previously published literature, and various mineralogical datasets that are publicly available via the world-wide web (e.g., http://webmineral.com and http://mindat.org).

Depending on a mineral's internal structure, particle shapes may take on various forms (Griffen, 1992). For example, calcite can display a variety of crystal habits including acute rhombohedra (Farmer, 1974), or prisms (http: //mindat.org), while clays tend to form flat plates (E. A. Reid et al., 2003). Although realistic dust particle morphologies and their distributions are far more complex, we baseline our study by analyzing monodispersed shape distributions (SD) of common geometrical shapes related to the minerals' crystal habits. Later in Sect. 4, the sensitivity of MEE to polydispersed SD is investigated.

In total, nine basic shapes are investigated: spheres, oblate and prolate spheroids, hexagonal columns and plates, hexahedrons (cubes and rectangles), tetrahedrons and irregular grains. The hexagonal and hexahedral structures make up the primary shapes used in this study (i.e., those that closest resemble reality and are nearest to what is known/documented), with the remaining shapes being secondary, since these too are possible and are commonly used in contemporary research. The rational and physical bases for the shapes, along with particle densities are presented in Table 3.

\section{Theory and numerical scheme}

Hand et al. (2007) describe the theory for calculating MEE of aerosol particles. For convenience, a summary of the theoretical approach in the context of a uniform, homogenous dust mixture is provided, followed by methodology.

\subsection{Theoretical approach}

The bulk single-scattering properties at wavelength $\lambda$ for a homogenous ensemble of randomly oriented dust particles having identical shape parameters can be computed if the distribution of particle sizes is known. For a given number distribution $n_{N}\left(D_{\mathrm{p}}\right)$ in the size range $D_{\mathrm{p} 1}$ to $D_{\mathrm{p} 2}$, and mineral composition specified by the complex refractive index $(m)$, the extinction coefficient $\left(\beta_{\mathrm{e}}-\right.$ in units of $\left.\mathrm{cm}^{-1}\right)$ for dust assuming volume equivalence (refer to Otto et al., 2009), can be written as:

$\beta_{\mathrm{e}}=\int_{D_{\mathrm{p} 1}}^{D_{\mathrm{p} 2}} \frac{\pi}{4} D_{\mathrm{p}}^{2} Q_{\mathrm{e}}\left(m, D_{\mathrm{p}}\right) n_{N}\left(D_{\mathrm{p}}\right) d D_{\mathrm{p}}$

where $Q_{\mathrm{e}}$, the optical extinction efficiency, is equal to the ratio of the extinction cross section $\left(\sigma_{\mathrm{e}}\right)$ to the projected area of a volume-equivalent sphere:

$$
Q_{\mathrm{e}}\left(m, D_{\mathrm{p}}\right)=4 \sigma_{\mathrm{e}} / \pi D_{\mathrm{p}}^{2}
$$

Note the wavelength dependency is implied in Eqs. (3-4). If the mineral density $(\rho)$ is known, Eq. (3) can be rewritten in terms of a mass distribution $n_{M}\left(D_{\mathrm{p}}\right)$, and when normalized by the total mass concentration $(M)$, the dust MEE $\left(\alpha_{\text {ext }}-\right.$ units of $\mathrm{m}^{2} \mathrm{~g}^{-1}$ ) at wavelength $\lambda$ is defined as:

$$
\alpha_{\mathrm{ext}}=\int_{D_{\mathrm{p} 1}}^{D_{\mathrm{p} 2}} 1.5 \frac{Q_{\mathrm{e}}\left(m, D_{\mathrm{p}}\right)}{\rho D_{\mathrm{p}}} n_{M}\left(D_{\mathrm{p}}\right) d D_{\mathrm{p}}
$$

where the single particle MEE $\left(\alpha_{\mathrm{sp}}-\right.$ units of $\left.\mathrm{m}^{2} \mathrm{~g}^{-1}\right)$ is given by:

$\alpha_{\mathrm{sp}}=1.5 \frac{Q_{\mathrm{e}}\left(m, D_{\mathrm{p}}\right)}{\rho D_{\mathrm{p}}}$

Similarly, the above equations can be employed to calculate both the single particle MSE and MAE. 
Table 3. Densities and shapes of common dust minerals.

\begin{tabular}{|c|c|c|c|}
\hline Mineral & $\begin{array}{c}\rho^{\mathrm{a}} \\
\mathrm{gcm}^{-3}\end{array}$ & Crystal habit $^{\mathrm{a}}$ (documented) & Primary shapes in study \\
\hline \multicolumn{4}{|l|}{ Silicates } \\
\hline Quartz & 2.65 & Hexagonal prism; pyramid on end Huggins et al. (1922) & Hexagonal column $(\mathrm{HC})^{\mathrm{e}}$ \\
\hline Kaolinite & 2.60 & Pseudo-hexagonal crystal plate; could be fibrous or spherical ${ }^{b}$ & Hexagonal plate $(\mathrm{HP})^{\mathrm{e}}$ \\
\hline Illite & 2.75 & Pseudo-hexagonal crystal plate ${ }^{b}$ & Hexagonal plate \\
\hline Montmorillonite & 2.35 & Pseudo-hexagonal crystal plate ${ }^{b}$ & Hexagonal plate $\mathrm{e}^{\mathrm{e}}$ \\
\hline Muscovite & 2.82 & Crude hexagonal cross-section; platy ${ }^{\mathrm{b}}$ & Hexagonal plate $\mathrm{e}^{\mathrm{e}}$ \\
\hline Chlorite & 2.95 & Barrel/tabular with hexagonal outline - compact/platy ${ }^{\mathrm{c}}$ & Hexagonal column ${ }^{\mathrm{e}}$ \\
\hline \multicolumn{4}{|l|}{ Carbonates } \\
\hline Calcite & 2.71 & $\begin{array}{l}\text { Rhombohedron (e.g., skewed rectangle). } \\
\text { Tabular form, prism; long spiny crystal }\end{array}$ & Rectangle/Cube \\
\hline Dolomite & 2.87 & Rhombohedron $^{\mathrm{d}}$ & Rectangle/Cube \\
\hline \multicolumn{4}{|l|}{ Sulfates } \\
\hline Gypsum & 2.30 & Tabular (rectangular); Bladed rosettes ${ }^{\mathrm{d}}$ & Rectangle/Cube \\
\hline \multicolumn{4}{|l|}{ Iron-oxides } \\
\hline Hematite & 5.30 & Rhombohedron $^{\mathrm{d}}$ & Rectangle/Cube \\
\hline
\end{tabular}

Tetrahedron - although Si-O bonds are tetrahedral, additional cationic groups usually precludes this configuration.

Nevertheless the possibility is considered.

Grain - In planetary/astrophysical studies, dust is commonly modeled as irregular-sized dust grains e.g., Kalashnikova et al. (2005);

Draine and Weingartner et al. (1996).

For this the Draine and Weingartner (1996) model (DW96), an array of 13 identical cubes, is employed.

Spheroid - analysis of dust samples E. A. Reid et al. (2003); Okada et al. (2001) reveals particles to usually be oblate spheroids (aspect ratio 1.4-1.9). Here oblate and also prolate spheroids are examined.

Sphere - although usually not observed in nature, the possibility is considered; also serves as reference for past works.

a Data obtained from online mineral databases, past literature, and field studies.

b Glotch et al. (2007) ; E. A. Reid et al. (2003); Kalashnikova et al. (2004).

c Kerr (1959).

d Farmer (1974); http://mindat.org.

${ }^{\mathrm{e}}$ (HC) Aspect ratio $L / 2 a_{\mathrm{eff}}=2$ ( $L=$ column length; $a_{\mathrm{eff}}=$ effective radius); (HP) $L / 2 a_{\mathrm{eff}}=0.5$.

\subsection{Methodology}

\section{Light-scattering codes}

To investigate the effects of particle asphericity on dust MEE, three light scattering codes are employed: Lorenz-Mie, Tmatrix, and Discrete Dipole Approximation (DDA). The first two methods, used to simulate rotationally symmetric and smooth particles (e.g., spheres, spheroids, and cylinders), are fully described in Mishchenko (1994, 1998). Similar to the Finite Difference Time Domain (FDTD) method (e.g., Yang and Liou, 1995), DDA (e.g., Draine and Flatau, 2004) is a numerical technique for solving the electromagnetic scattering problem used to compute the single-scattering properties of irregularly shaped, inhomogeneous particles.
This study uses DDSCAT program version 6.1 (Draine and Flatau, 2004) for computing the optical extinction efficiencies $\left(Q_{\mathrm{e}}\right)$ of irregularly-shaped dust particles. In brief, the DDA method discretizes an arbitrarily shaped particle into an array of point dipoles (i.e., polarizable points) on a cubic lattice, which interact with a monochromatic plane wave characterized by wavelength $\lambda$ and incident polarization vector $\boldsymbol{e}_{\boldsymbol{o}}$. The computed single-particle extinction efficiency $\left(Q_{\mathrm{e}}\right)$ averaged over random orientations of the particle is given by:

$$
\left\langle Q_{\mathrm{e}}\right\rangle=\frac{1}{8 \pi^{2}} \int_{0}^{2 \pi} d \delta \int_{-1}^{1} d \cos \Theta \int_{0}^{2 \pi} d \phi Q(\delta, \Theta, \phi)
$$

where angles $\delta, \Theta$, and $\phi$ specify the particle's orientation in the lab frame. Considering the point symmetry of 
our particle shapes and the demanding computational requirements of DDA over all prescribed dust parameterizations and wavelengths, $\left\langle Q_{\mathrm{e}}\right\rangle$ was computed by averaging over a total of $N=12$ orientation angles. Sensitivity of the model results to an increase in particle orientations (e.g., $N=1050$ ) for an asymmetric kaolinite-hematite grain mixture, for example, reveals absolute differences in $\left\langle Q_{\mathrm{e}}\right\rangle\left[\left\langle Q_{\mathrm{e}}\right\rangle_{N=12}-\left\langle Q_{\mathrm{e}}\right\rangle_{N=1050}\right] \leq 0.08 \mathrm{~m}^{2} \mathrm{~g}^{-1}$ (Fig. 2), with the maximum difference corresponding to the mineral's peak absorption bands. Since all particles in this study with the exception of irregular grains are rotationally symmetric, we expect any errors with using a reduced set of orientation angles to be at most $\sim 0.08 \mathrm{~m}^{2} \mathrm{~g}^{-1}$ across the thermal IR.

Following Draine (2000), accurate DDA calculations of the optical cross-sections (within several percent) are achieved if (1) an adequate number of dipoles $(N)$ are specified $(N>10000),(2)$ the inter-dipole separation $(d)$ is smaller than the wavelength of incident radiation $(\lambda)$ : $m k^{\prime} d<1$, where $m$ is the particle's complex refractive index, and $k^{\prime}$ is the free-space wave number $(2 \pi / \lambda)$, and (3) the refractive index is not too large: $|m-1|<2$.

The above criteria are illustrated in Fig. 3 assuming $N=10001$ dipoles, where Fig. 3a and b show the maximum inter-dipole separation and extreme refractive index $(m)$ test, respectively, for select minerals across the window region. Although gypsum slightly exceeds the $\mathrm{m}$ test threshold at $9 \mu \mathrm{m}$ (Fig. 3b), the error should not significantly impact the MEE results. All DDA computations are performed using $N>10001$ dipoles.

\section{Numerical approach}

For this study we compute MEE and MAE at discrete wavelengths from the near to thermal IR. Model simulations are evaluated at the wavelengths $\lambda=0.87,1.04,1.6,2.12,3.75$, $8,8.6,9,10,11$, and $12 \mu \mathrm{m}$ (Lorenz-Mie and T-matrix) and $\lambda=8,8.5,9,9.5,10,10.5,11,11.5,12$, and $12.5 \mu \mathrm{m}$ (DDA). These wavelengths were chosen since they are commonly used in ground and satellite-based remote sensing such as those from AERONET (Holben et al., 1998) and the MODIS and MISR programs (e.g., Levy et al., 2007; Kahn et al., 2007). Although dust optical properties exhibit a spectral dependence at the visible wavelengths (e.g., Müller et al., 2009), we use the properties at $\lambda=0.870 \mu \mathrm{m}$ as a proxy for representing wavelengths down through the green to avoid the extreme computational cost at the shorter wavelengths. This point is later addressed in Sect. 4. Furthermore, wavelengths at $\lambda=12 \mu \mathrm{m}$ reach the most commonly used satellite IR bands.

The refractive indices of all mineral datasets (Table 1) are pre-processed to include only the selected wavelengths. Exceptions made are for those minerals where there was little or no information available on the refractive indices at the near-IR wavelengths, including muscovite, dolomite, calcite,

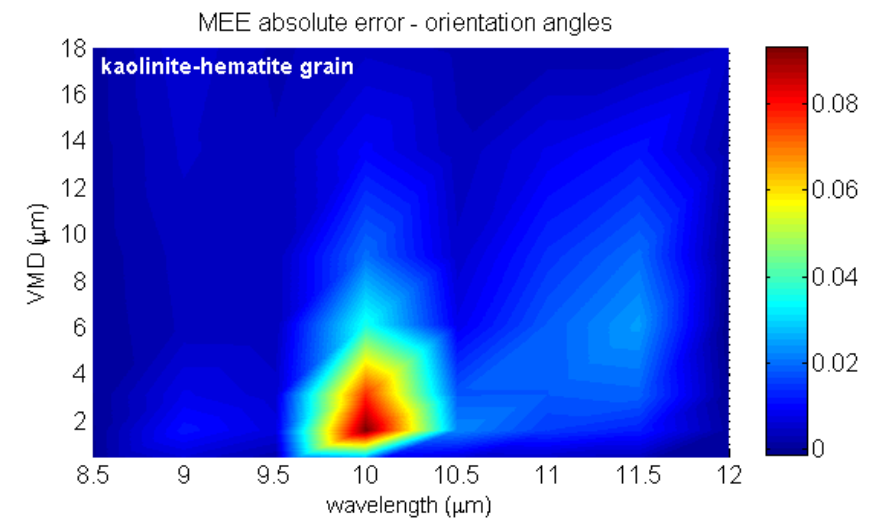

Fig. 2. Absolute error in MEE between using a reduced number of orientation angles $(N=12)$ versus an extended set $(N=1050)$ for an asymmetric kaolinite-hematite grain mixture (units are in $\left.\mathrm{m}^{2} \mathrm{~g}^{-1}\right)$. See text for details.
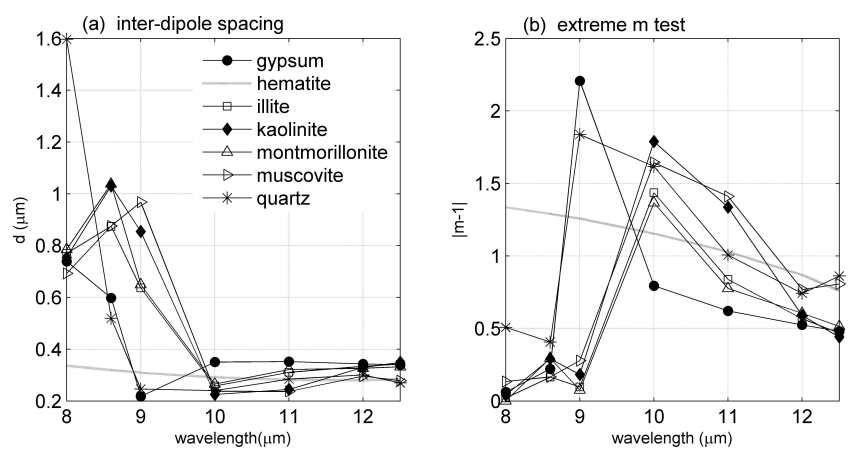

Fig. 3. DDA applicability criteria versus wavelength $(\lambda)$ and mineral composition for (a) maximum inter-dipole spacing $d(\mu \mathrm{m})$ and (b) large refractive index $m$. See text for details.

and chlorite. These minerals were therefore only evaluated from $\lambda=3.75-12 \mu \mathrm{m}$. For illite and kaolinite, we combined the near-IR and IR datasets into one spectral dataset. As previously noted (Sect. 2.1), effective refractive indices were computed for birefringent minerals, and the MG Rule was applied to create two component internal mixtures of silicates and hematite.

The Lorenz-Mie and T-matrix light scattering codes were employed for particle sizes in the range of $0.05-12 \mu \mathrm{m}$, for spheres and spheroids, respectively. Aspect ratios for spheroids were varied as follows: oblate $(1.4,1.8,2.3$, and $2.8)$, and prolate $(0.3,0.5$, and 0.8$)$. Limitations in the size parameter for DDA $(\chi<15)$ imposed additional constraints for accurately computing $\left\langle\alpha_{\mathrm{sp}}\right\rangle$ for coarse-mode particles at the visible wavelengths. For this reason, we only use DDA to compute the size integrated MEE spectra for each discrete shape in the thermal IR. However, to help understand the discrete shape effect on MEE at visible wavelengths $(\lambda=$ $0.86 \mu \mathrm{m})$, we use the computed $\left\langle\alpha_{\mathrm{sp}}\right\rangle$ from Kalashnikova et 
al. (2004) for several angular shapes composed of a $10 \%$ hematite-quartz mixture.

The bulk MEE ( $\left.\left\langle\alpha_{\text {ext }}\right\rangle\right)$ for a monodispersed SD was numerically computed for each set of dust parameters at each wavelength $(\lambda)$ using the expression:

$$
\left\langle\alpha_{\mathrm{ext}}\right\rangle=\sum_{j=D_{\mathrm{p} 1}}^{D_{\mathrm{p} 2}}\left(\alpha_{\mathrm{sp}}\right)_{j}\left(n_{M}\left(D_{\mathrm{p}}\right)\right)_{j} \cdot \Delta D_{\mathrm{p}}
$$

where $j$ is a summation over particle size $\left(D_{\mathrm{p}}\right)$ and $\alpha_{\mathrm{sp}}$ is the single-particle MEE. The bulk MAE was computed in a similar manner. For polydisperse SD, such as those used to assess the two possible dust scenarios described in Sect. 2, we weight $\left\langle\alpha_{\text {ext }}\right\rangle$ according to how much each mineral habit contributes to the total MEE.

The parameter space covering the total computed MEE spectral envelope is defined by 12 mineral compositions ( 9 pure minerals +3 silicate-hematite (10\%) mixtures), 14 particle morphologies ( 6 angular +7 spheroidal +1 spherical), 7 particle sizes, and 11 channels covering the near-IR and IR regions of the spectrum, including the 10 sub-divided window channels. In total, 12442 possible MEE values define the spectral envelope for this study. Furthermore, MEE spectral data constructed from field and laboratory measurements including the Hess/OPAC dust and dust-soot parameterizations, high and low dust scenarios from SAMUM 2006, and 2 silicate-hematite (2\%) mixtures, yields a total of 4994 MEE reference values.

\section{Model results}

First the significance of dust absorption (MAE) on the total MEE over the thermal IR is examined. Next, plausible ranges and trends of MEE are presented, followed by its sensitivity to the dust parameterizations. Spectral MEE are then compared to identify relationships in the optical properties and finally a short discussion on potential applications is given.

\subsection{Dust absorption}

MAE plays a major role in the extinction properties of mineral dust throughout the thermal IR, yet is nearly zero across the near-IR (MSE > > MAE), except when hematite is added to the mixture (not shown). Examples of prominent absorption features for common minerals in the IR are clearly illustrated in Fig. 4. Here we show normalized MAE $(\times 100 \%)$ for several representative silicates (quartz, kaolinite, illite), sulfate (gypsum), mica (muscovite), and for reference, the OPAC/Hess dust parameterization. The color bar represents the percentage of particle extinction due to absorption and the horizontal and vertical axes are the particle size (VMD) and wavelength $(\lambda)$, respectively. Noteworthy are the regions of enhanced MAE (color-coded red and yellow), which are later referred to as "hot-spots" or areas that are characterized by the minerals' strong absorption features (reststrahlen bands), and their dependency on VMD. Pockets of weaker absorption (color-coded blue) are those regions marked by corresponding increases in scattering or MSE. The partitioning of the dust particle's MAE and MSE is also shown as a function of VMD. The MAE distribution for quartz (Fig. 4a), for example, distinguishes three distinct regimes of particle absorption, which includes the resonant peaks near $8.3,9.2$ and $12 \mu \mathrm{m}$, separated by a scattering region from $\lambda=10-11 \mu \mathrm{m}$, where particle absorption is nearly zero (refer to Fig. 1c).

Apparent at the IR wavelengths is the reduction in fractional MAE as VMD increases, which means that scattering generally contributes more to the MEE of larger size particles; this being analogous to the simple Fresnel reflectance of a solid surface (Salisbury, 1991). Compared to quartz, the clays kaolinite (Fig. 4b) and illite (Fig. 4c), and the mica muscovite (Fig. 4d) exhibit broader spectral ranges of particle absorption throughout much of the window region. Interestingly, the MAE distribution for Hess/OPAC dust (Fig. 4e) is similar to that of the quartz and clays, which comes as no surprise since Hess/OPAC is essentially a heterogeneous dust mixture consisting of the silicate minerals (note that the refractive indices of OPAC/Hess are predominantly derived from D'Almeida (1991), which in turn reference Shettle and Fenn (1979) and Volz (1973). We also plot the sulfate gypsum (Fig. 4f) which exhibits strong absorption around $8 \mu \mathrm{m}$ and then transitions over to a region dominated mostly by scattering.

\subsection{Ranges in dust MEE}

Following Eq. (8), dust MEE values were computed and subsequently grouped according to wavelength to determine a maximum plausible range of MEE for the channels investigated. Note the discussion that follows reflects the entire parameter space over which this study was conducted, and illustrates the impact of extreme dust chemistry and microphysics on MEE. Numerical tables of MAE/MEE for the common dust minerals kaolinite, gypsum and quartz, are publicly available on-line. The full datasets can be provided upon request to the authors.

Figure 5a illustrates the variability in MEE over all spectral channels (near-IR-IR), where the values at each wavelength represent the maximum MEE over the entire range of seven particle sizes for each composition and shape combination investigated. Figure $5 \mathrm{~b}$ is an enlarged view of the same plot but in the thermal IR showing the minerals which correspond to the maximum MEE at each wavelength. For convenience, the curves are color-coded according to particle morphology: white for spheroids (oblate/prolate), red for spheres, and yellow for angular particles. Note the MEE values between channels are interpolated and therefore do not have any physical meaning. For reference purposes, MEE data based on previous laboratory and field studies (Hess/OPAC dust and dust-soot parameterizations, SAMUM 

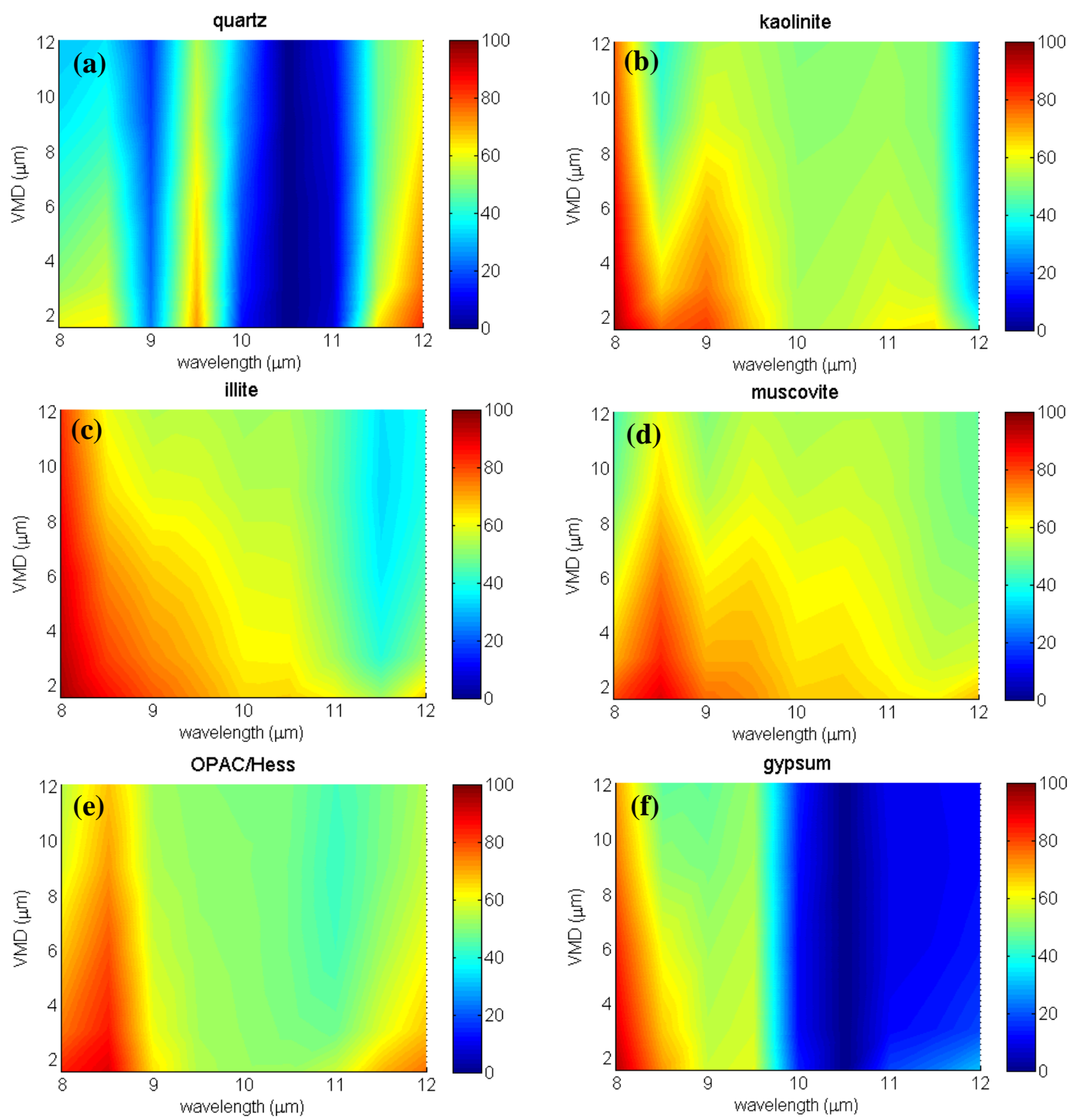

Fig. 4. MAE as a percentage of MEE for common dust minerals across the thermal IR including (a) quartz (rectangle), (b) kaolinite (plate), (c) illite (plate), (d) muscovite (grain), (e) Hess/OPAC (plate) and (f) gypsum (rectangle). The vertical and horizontal axes are the particle VMD and wavelength, respectively. The color bar denotes the percentage of particle extinction due to absorption. Note the unique positions and shapes in the absorption features for each mineral composition. See text for details.

2006 high/low dust scenarios, and a kaolinite- $2 \%$ hematite mixture) are shown in Fig. 5c.

In Fig. 5a, two dominant peaks of the spectral envelope are clearly evident: one at $\lambda=0.87 \mu \mathrm{m}$ and the other at $\lambda=9.0 \mu \mathrm{m}$, with maximum MEE values clustered near $\alpha_{\text {ext }}=1.18$ and $1.28 \mathrm{~m}^{2} \mathrm{~g}^{-1}$, respectively. Considering the Hess/OPAC dust-soot (DS) mixture, the maximum MEE values increase to $\alpha_{\mathrm{ext}}=1.32$ and $1.29 \mathrm{~m}^{2} \mathrm{~g}^{-1}$, respectively. Note the $0.87 \mu \mathrm{m}$ peak does not include angular particles. Larger MEE values of the dust-soot mixture in the near-IR for spheres and spheroids are indicated by the black arrows. A third smaller peak is also apparent at $\lambda=10 \mu \mathrm{m}$. The MEE differ by about an order of magnitude with minimum values falling below $\alpha_{\text {ext }}=0.1 \mathrm{~m}^{2} \mathrm{~g}^{-1}$. Both maxima are attributed to non-spherical particles (oblate spheroids) with the first being mostly composed of gypsum, with contributions from the clays illite, kaolinite, and montmorillonite, and also the clay-hematite mixture, since hematite is a strong absorber at the visible/near-IR wavelengths. Although quartz does contribute to the first peak, its presence mainly dominates the second maximum due to the strong absorption band centered at $9.2 \mu \mathrm{m}$ (Fig. 5a).

Interestingly in Fig. 5b, the resonance peak for a quartz sphere (dashed red curve with square) appears to be blueshifted by almost $0.5 \mu \mathrm{m}$ with respect to a quartz non-sphere (e.g., an oblate spheroid - dashed white curve with square), 

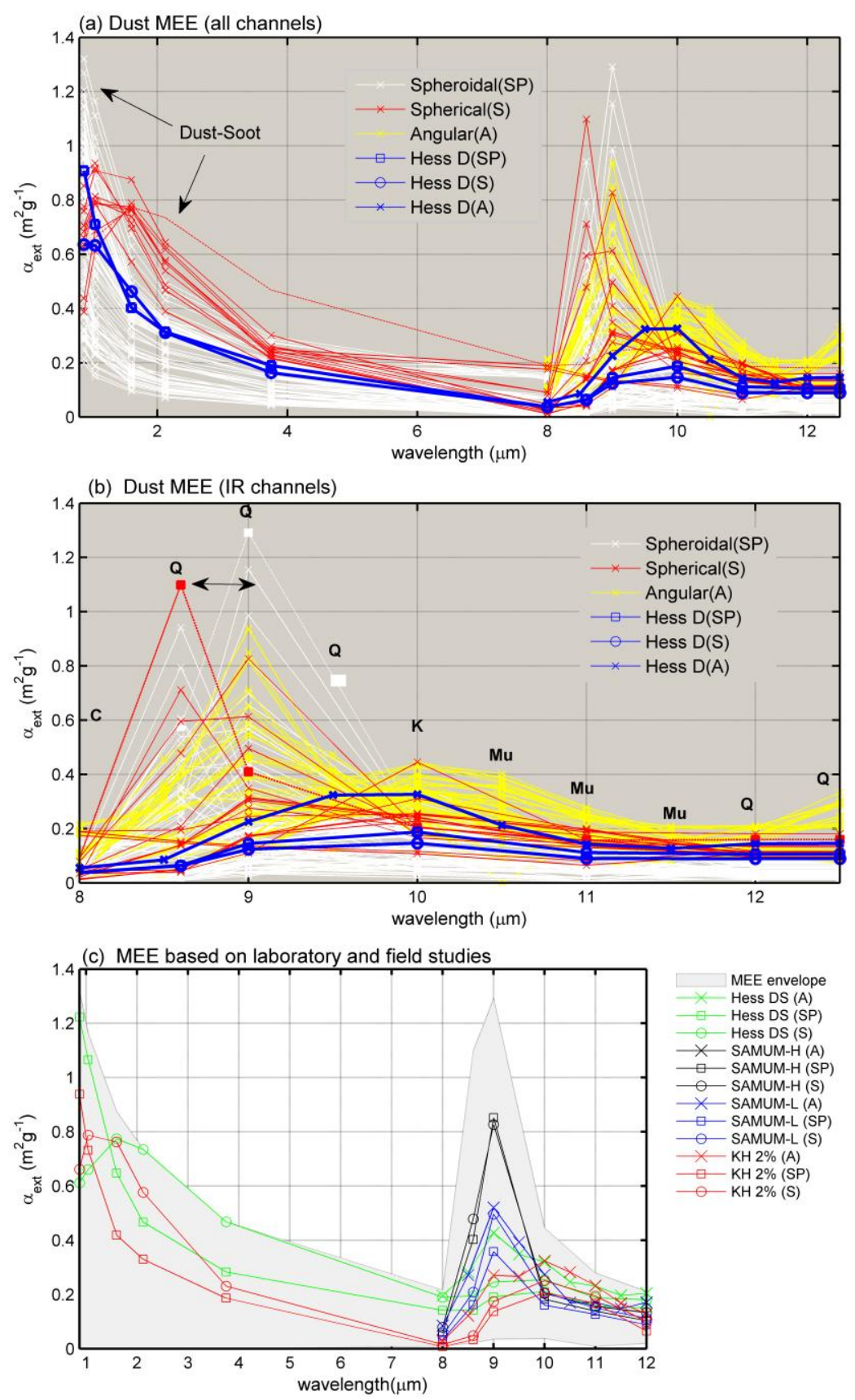

Fig. 5. (a) Maximum dust MEE over all dust parameterizations and wavelengths (channels). The Hess/OPAC dust (D) model is represented by the blue curves. (b) Same as (a) but in the thermal IR. The black arrow denotes the spectral shift between spherical and non-spherical quartz particles (dotted red and white curves, respectively, with squares). The letters C (calcite), Q (quartz), K (kaolinite), and Mu (muscovite) represent the minerals that have the maximum MEE at each wavelength (c) typical scenarios of MEE spectra based on laboratory and field studies. See text for details.

but is also observed for the quartz angular particles (yellow curves) as well (this is clearly shown later in Fig. 7) . Note the black arrow denotes the spectral shift between the quartz particles. A large spectral shift was also detected for the clay minerals, where montmorillonite for example, which has a strong absorption peak around $\lambda=9.6 \mu \mathrm{m}$ (Manghnani et al., 1964) showed spheres and angular particles to differ by nearly $1 \mu \mathrm{m}$. Although the observed spectral shifts are likely to be overestimated due to the coarse resolution in the computed MEE spectra, the results clearly demonstrate, similar to that reported by Hudson et al. (2008), that Mie simulations can not accurately reproduce the peak positions of silicate 

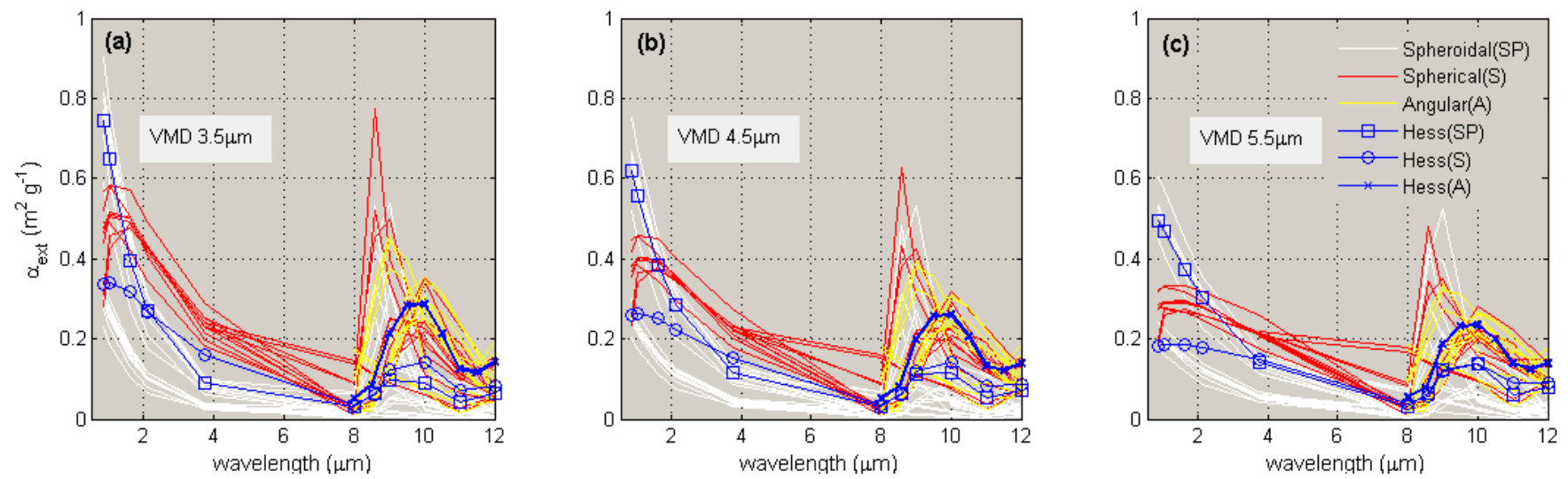

Fig. 6. Dust MEE over all particle shapes, compositions and wavelengths (channels) with VMD corresponding to the frequently observed size range of (a) $3.5 \mu \mathrm{m}$, (b) $4.5 \mu \mathrm{m}$, and (c) $5.5 \mu \mathrm{m}$. Shapes consist of oblate and prolate spheroids (SP) with aspect ratios of 1.8 and 0.5 , respectively, spheres (S), and angular particles (A), calculated only for IR wavelengths for all 13 mineral compositions. The Hess/OPAC dust model is represented by the blue curves.

minerals, i.e. quartz $(9.2 \mu \mathrm{m})$ and clays $(\sim 10 \mu \mathrm{m})$. On the other hand, non-spherical shapes are able to better reproduce the minerals' true spectral features and should be used when modeling dust aerosol.

The MEE values based on laboratory and field data (Fig. 5c) were found to lie within the bounds of the spectral envelope. Those from the spherical Hess/OPAC dustsoot mixture occupied the upper bound of the envelope from 2.12-8 $\mu \mathrm{m}$, while those from SAMUM 2006 for high dust conditions, for example, exhibited maximum values near $\alpha_{\text {ext }}=0.8 \mathrm{~m}^{2} \mathrm{~g}^{-1}$.

If we restrict dust particle size to what is commonly measured in the field, i.e. VMD between 3-6 $\mu \mathrm{m}$ (J. S. Reid et al., 2003), and use an aspect ratio of 1.8 for oblate spheroids, consistent with observations (Chou et al., 2008; Müller et al., 2010; E. A. Reid et al., 2003), then a more representative range of MEE spectra are given as shown in Fig. 6, where panels $(\mathrm{a}-\mathrm{c})$ are for a VMD of $3.5,4.5$, and $5.5 \mu \mathrm{m}$, respectively. As before, the curves are color-coded according to particle morphology and the blue curves depict the Hess/OPAC parameterization for dust. The same two dominant peaks at $\lambda=0.87 \mu \mathrm{m}$ and $\lambda=9.0 \mu \mathrm{m}$ (including the third smaller peak at $\lambda=10 \mu \mathrm{m}$ ) have maximum MEE values approaching nearly $\alpha_{\text {ext }}=0.9$ and $0.8 \mathrm{~m}^{2} \mathrm{~g}^{-1}$, respectively, with minimum values about an order of magnitude smaller. The bifurcation in the spheroidal MEE spectra (white curves), are due to the extreme differences in aspect ratios, where the upper/lower groups represent aspect ratios of 1.8 and 0.5 (prolate), respectively. The MEE spectra for prolate spheroids are smaller due to the larger projected areas.

At the shorter wavelengths $(\sim \lambda=0.87 \mu \mathrm{m})$, trends in MEE were found as a function of VMD for spherical particles, consistent with those reported in J. S. Reid et al. (2003), i.e. as VMD goes up, the MEE decreases as $\mathrm{VMD}^{-a}$, where $a \approx 1$; however non-spherical effects appear to play a role in the MEE (VMD) response curves. Non-spherical MEE values at larger VMD do not fall off as quickly as do spheres (i.e., $a<<1$ ); hence we see larger MEE values for particles with higher VMD. Likewise, in the thermal IR we see similar effects, where MEE values generally appear to be larger with VMD and in fact at times, the MEE clearly increase with VMD as in the case of the pure mineral kaolinite, for example. The MEE (VMD) response in the thermal IR yields interesting physics which seems to be strongly tied with the particles' composition and wavelength.

\subsection{Sensitivity of MEE to dust microphysics and chemistry}

\section{Preliminary assessments and trends}

Examples depicting changes in MEE in response to perturbations in the dust physicochemical properties are illustrated in Fig. 7. Presented are MEE surface plots corresponding to each combination of dust parameters, where the rows and columns represent particle mineralogy and morphology, respectively. Here the VMD is defined for a coarse-mode size distribution with the baseline geometric standard deviation $\left(\sigma_{\mathrm{g}}\right)$ of 2.0 which we later adjust to assess the corresponding changes in MEE (see Sect. 4.3 - Particle size). The color bar depicts the MEE intensity where an upper value cutoff of $\alpha_{\mathrm{ext}}=0.6 \mathrm{~m}^{2} \mathrm{~g}^{-1}$ was chosen to help resolve the fine structure detail in the MEE distributions.

The panels share common regions which exhibit higher MEE intensity values ranging from $\sim 0.3$ to $>0.6 \mathrm{~m}^{2} \mathrm{~g}^{-1}$ which, like the MAE distributions in Fig. 4, are referred to as "hot-spots". These sharply contrast against the background MEE which are typically $\leq 0.2 \mathrm{~m}^{2} \mathrm{~g}^{-1}$. A quick inspection of the panels immediately reveals several interesting features. 

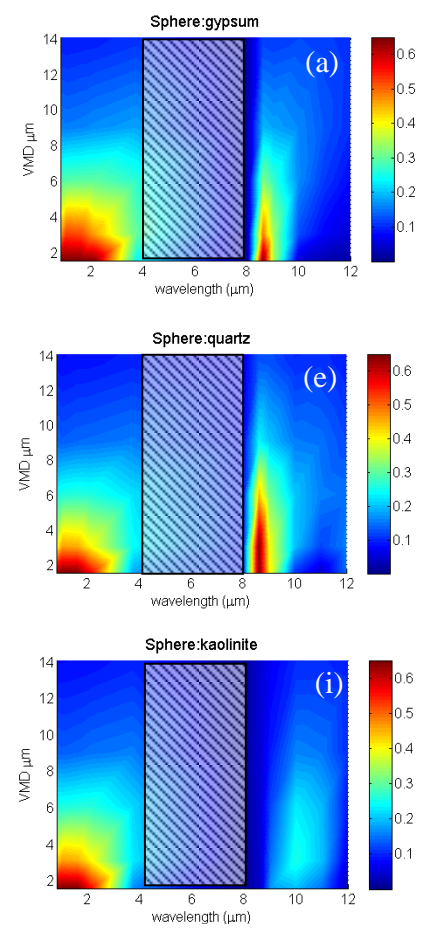

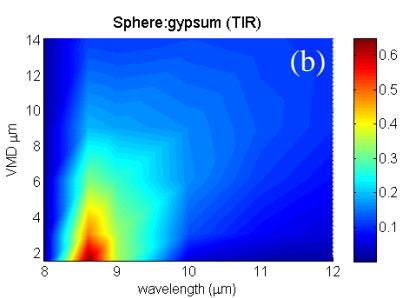

Sphere:quartz (TIR)
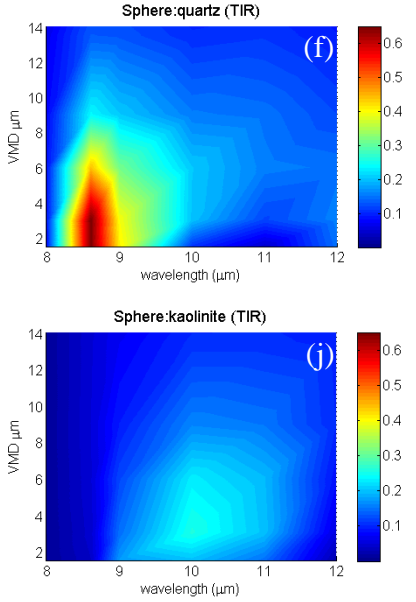
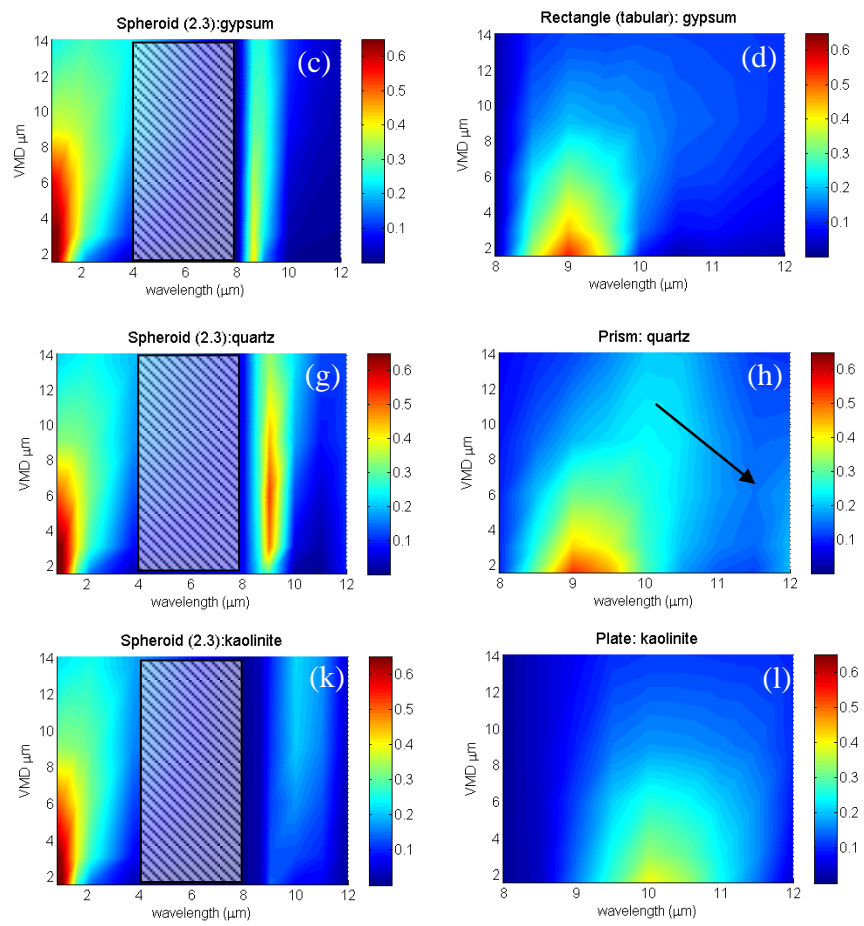

Fig. 7. Surface plots depicting MEE distributions (units are in $\mathrm{m}^{2} \mathrm{~g}^{-1}$ ) for several key minerals as functions of particle chemistry (rows), particle morphology (columns - note the 2nd and 4th columns are only for IR wavelengths), and particle size (VMD) and wavelength $\lambda$ (vertical and horizontal axes, respectively). Columns 2 and 4 compare MEE for spheres and angular particles in the thermal IR (TIR). Gray hatched boxes denote data gap between $\lambda=3.75-8 \mu \mathrm{m}$. Note the changes in MEE distributions (hot-spots) when dust parameters are perturbed.

1. The shapes and positions of hot-spots vary depending on mineral type, and the particle's respective size and shape. Particularly notable are the differences between minerals, where the hot-spots are related to absorption band number, position, shape and depth. For example, the quartz prism in Fig. 7h exhibits two hot-spots in the IR: one due to the dominant fundamental asymmetric OSi-O stretching vibration near $9.2 \mu \mathrm{m}$ and another that is less apparent due to the weaker symmetric O-Si-O stretching vibration around $12 \mu \mathrm{m}$ denoted by the black arrow (Farmer, 1974). Evidently, the latter region is not so easily discerned in the smooth particles (e.g., compare Fig. 7e through 7g). Kaolinite plates (Fig. 71), on the other hand, have one hot-spot centered near $10 \mu \mathrm{m}$. The central positions of the hot-spots are nearly consistent with the peak vibrational frequencies of each mineral as noted by Karr et al. (1975): quartz $(9.2 \mu \mathrm{m})$ and kaolinite $(9.6-9.7 \mu \mathrm{m})$.

2. At the shortest wavelength $(\lambda=0.870 \mu \mathrm{m})$, the MEE increases as VMD decreases, since particle size is on the order of the incident wavelength.

3. The hot-spots appear to follow the particle's geometry, particularly spheroids, and are evidence for shape dependency in the optical properties. For example at the shorter wavelengths, the hot-spots associated with spherical particles (Fig. 7a, e, and i) appear to be more rounded and distributed symmetrically over the size and wavelength domains (VMD $\sim 1-6 \mu \mathrm{m}$ and $\lambda=$ $0.870-3.75 \mu \mathrm{m}$, respectively), whereas those for oblate spheroids (spheres stretched along the equatorial axis - see Fig. 7c, g, and k) are more elongated with respect to particle size and are more narrowly confined in wavelength. Notable differences in the hot-spots of angular particles are also apparent both in intensity and position (e.g., gypsum - Fig. 7d and quartz - Fig. 7h), and are consistent with the spectral features reported in previously published literature (e.g., Karr et al., 1975; Farmer et al., 1974; Salisbury et al., 1991). For example, the spectral shifts in MEE between spheres and angular quartz particles (Fig. 5b) can be seen by comparing Fig. $7 \mathrm{f}$ and $\mathrm{h}$. Generally, sharp-edged particles tend to produce wider and more symmetric MEE distribution patterns from about $8-10 \mu \mathrm{m}$ compared with spheres and spheroids, perhaps due to the edge effects in the optical properties of the particles. 
Trends noted in the MEE spectra are as follows. At the shorter wavelengths $(\lambda=0.87 \mu \mathrm{m})$, MEE generally tends to increase when going from spheres to spheroids (e.g., Figs. 5 and 6). To evaluate the shortwave effects on MEE due to discrete shapes, we use the computed $\left\langle Q_{\mathrm{e}}\right\rangle$ from Kalashnikova et al. (2004) for a quartz-hematite mixture (10\%) consisting of $1 \mu \mathrm{m}$ sized particles. The single particle MEE for several geometries including plates, irregular grains, tetrahedrons, and rectangles were calculated and were found to lie in the range of $0.81-1.19 \mathrm{~m}^{2} \mathrm{~g}^{-1}$, about 2-3 times greater than that of spheres (e.g., red curves in Figs. 5 and 6). Increases in MEE at short wavelengths are primarily due to enhancements in scattering (MSE), when MAE tends to zero.

Across the thermal IR, changes in MEE due to shape are strong functions of VMD and wavelength, particularly if MEE is evaluated at the mineral resonant frequencies where the absorption coefficients are high. At these frequencies, MAE and consequently MEE generally tend to increase when going from spheres to spheroids, particularly for larger particles; however, outside of these strongly absorbing regions, both MAE and MEE tend to decrease. Similar changes in MEE and MAE are also apparent when going from spheres to the discrete angular shapes. The behavior of MEE in the IR is strongly linked to changes in MAE which ultimately depend on both wavelength and VMD.

Next the effects of each parameter on the MEE spectra are examined in the order of particle chemistry, size, and morphology.

\section{Particle chemistry}

To illustrate the impact of chemistry on dust MEE, we analyze dust grains with a VMD of about $3 \mu \mathrm{m}$ (Fig. 8a), which roughly correspond to the median size of the MEE distributions. Note that granular particles have been routinely observed (E. A. Reid et al., 2003) and are commonly employed in optical dust models (Kalashnikova et al., 2005). The MEE spectra for six pure minerals (quartz, gypsum, illite, kaolinite, montmorillonite, and muscovite), one clay-hematite mixture (kaolinite-hematite), and one bulk dust parameterization (Hess/OPAC) are given. Immediately apparent are two dominant peaks in the spectra, one narrowly positioned at $9 \mu \mathrm{m}$ and another centered around $10 \mu \mathrm{m}$. Incidentally, a smaller third peak is also visible around $\lambda=12 \mu \mathrm{m}$ due to quartz. The second peak is more broadly distributed over wavelength than the first since there are a greater number of absorption bands, particularly for the clay minerals in the range of $\sim 9-11 \mu \mathrm{m}$. Note that both quartz and gypsum exhibit the strongest peaks over the thermal IR. This also includes the quartz-hematite mixture (not shown). Adding hematite to clays, shown by the green curve (squares) for a kaolinitehematite mixture, decreases MEE in the strongly absorbing region of $\lambda=9-11 \mu \mathrm{m}$. At $\lambda=10 \mu \mathrm{m}$, for example, MEE is reduced by almost $14 \%$ when kaolinite is internally
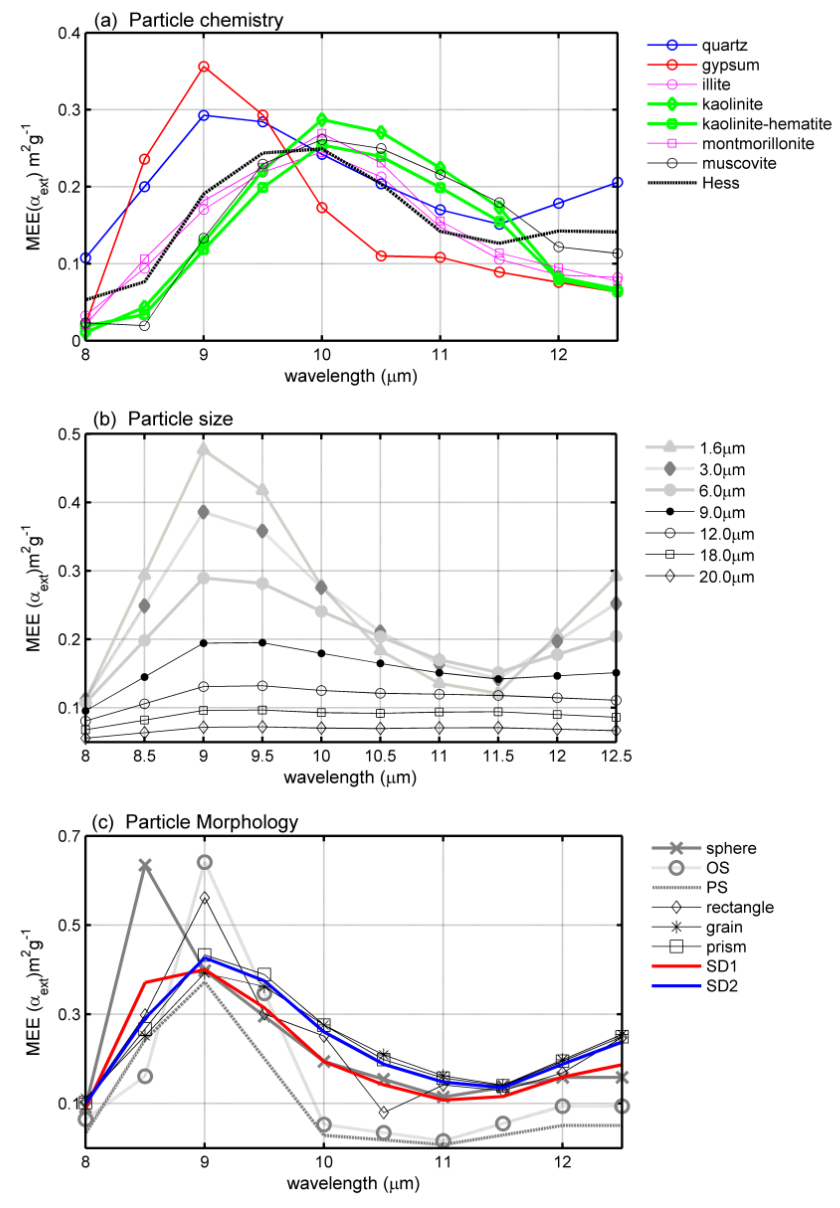

Fig. 8. Sensitivity of MEE to dust microphysics and chemistry (a) particle chemistry, (b) particle size (VMD), and (c) particle morphology. SD1 and SD2 are the particle shape distribution scenarios. See text for details.

mixed with $10 \%$ hematite (Sect. 2.1), although this is likely an overestimate for natural dust as the iron-oxide content in mineral dust typically does not exceed 5\% (Lafon et al., 2006). Further analysis of this effect is illustrated in Fig. 9, where the change in MEE (Fig. 9a), MAE (Fig. 9b), and MSE (Fig. 9c) are shown after hematite has been added (i.e. $\Delta M \times E=M \times E_{\text {hematite }}-M \times E_{\text {nohematite, }}$, where $x=E, A$, and $S$, respectively). Here, positive values denote regions of enhanced absorption and scattering due to the presence of hematite. Because kaolinite is a much stronger absorber than hematite in the thermal IR (compare Fig. 1c and d), the addition of hematite increases kaolinite's absorption efficiency (Fig. 9b) for all particle sizes at wavelengths between $\lambda=8-9 \mu \mathrm{m}$. This effect is sensitive to particle size where $\Delta M \times E$ falls off with an increase in VMD. This is also observed, albeit a weaker effect, in the MSE (Fig. 9c). Likewise, where absorption is weaker in kaolinite $(\lambda \sim 8-9 \mu \mathrm{m})$, the added hematite increases the kaolinite's absorption efficiency (Fig. 9b). These same patterns are similar for the other clays. 

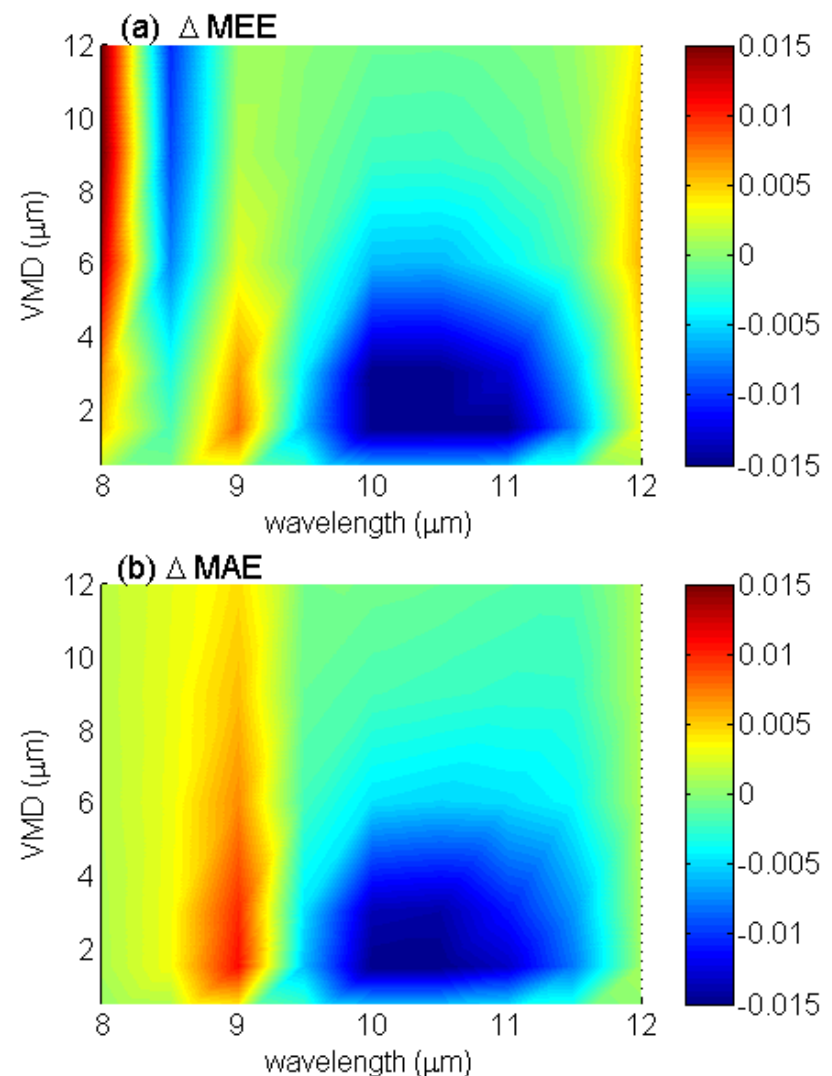

(c) $\triangle$ MSE

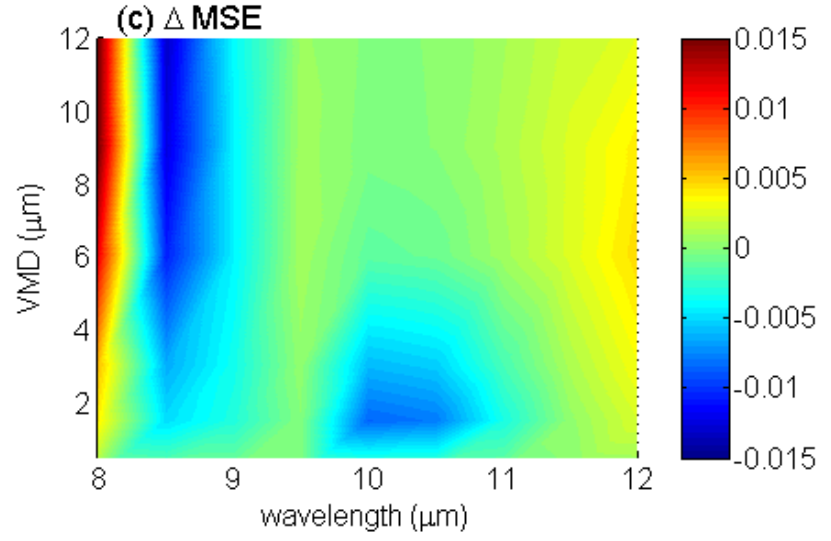

Fig. 9. Sensitivity of MEE to a clay-hematite mixture. Difference plots are shown for (a) $\triangle \mathrm{MEE}$, (b) $\triangle \mathrm{MAE}$, and (c) $\triangle \mathrm{MSE}$. All units are in $\mathrm{m}^{2} \mathrm{~g}^{-1}$. See text for details.

Lastly, it is evident that the MEE spectrum corresponding to the Hess/OPAC parameterization (Fig. 8a, dashed black curve) is a heterogeneous mixture of silicates and clays. Displaying a central peak around $10 \mu \mathrm{m}$, the spectrum resembles those for the clays, particularly illite; however from about $11-12 \mu \mathrm{m}$ the spectrum looks more similar to quartz. For many dust applications in the thermal IR, the Hess/OPAC parameterization represents a reasonable approach for modeling dust; particularly in regions where clays dominate. Where potential problems might arise, however, is when the

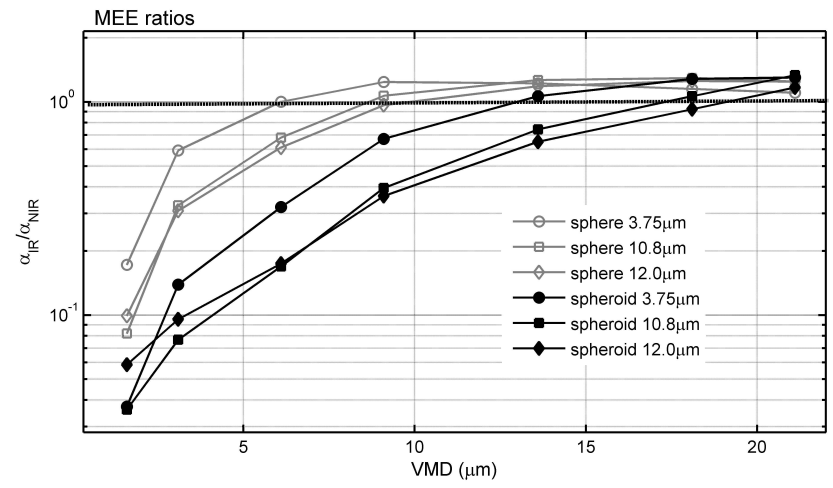

Fig. 10. Log scale of MEE ratios $\left(\alpha_{\mathrm{IR}} / \alpha_{\mathrm{NIR}}\right)$ versus VMD for the Hess/OPAC parameterization using spheres and oblate spheroids with aspect ratio 1.8. The IR wavelengths (legend) are the centers of AVHRR channels 3, 4, and 5, respectively. Refer to Table 4.

main dust component is either quartz or gypsum which can lead to errors in MEE of up to $100 \%$ for wavelengths between $8-9 \mu \mathrm{m}$. This corresponds to the $8.6 \mu \mathrm{m}$ channel widely used in many remote sensing applications. It is important to point out that these bulk dust models may miss the larger absorption features that are otherwise present in a homogeneous dust mixture. Potential errors may include the retrieval of key dust and surface parameters, and the quantitative assessment of DARE used in climate research.

\section{Particle size}

To illustrate the impact of particle size on dust MEE, we again choose to analyze granular quartz particles. Figure $8 \mathrm{~b}$ shows the resulting MEE spectra as a function of particle VMD which varies from 1.6-20.0 $\mu \mathrm{m}$ using the reference geometric standard deviation $\left(\sigma_{\mathrm{g}}\right)$ of 2.0. Note the largest changes in MEE occur at the peak absorbing wavelength $(\sim \lambda=9 \mu \mathrm{m})$ for particle sizes with a VMD in the range of $\sim 1.6-6 \mu \mathrm{m}$. At the remote sensing channels $(\lambda=8.6,11$, and $12 \mu \mathrm{m})$, MEE sensitivity to particle size is greatest at $\lambda=8.6 \mu \mathrm{m}$, where absolute differences in MEE can exceed $0.15 \mathrm{~m}^{2} \mathrm{~g}^{-1}$. For wavelengths between $\lambda=8.1$ $9.9 \mu \mathrm{m}$ and greater than $\lambda=12 \mu \mathrm{m}$, MEE clearly increases as VMD decreases, consistent with the shortwave calculations of J. S. Reid et al. (2003). (It is important to note that J. S. Reid et al., 2003 employed spheres and the refractive indices of Shettle and Fenn, 1979). Curiously, the correlation between MEE and VMD was not observed between $\lambda=10-12 \mu \mathrm{m}$, which may be directly related to the behavior of quartz particles at these wavelengths (refer to discussion on MEE vs. VMD - Sect 4.2).

To assess the sensitivity of MEE to changes in the $\sigma_{\mathrm{g}}$, we performed a series of tests in which $\sigma_{\mathrm{g}}$ was adjusted to \pm 0.3 of the reference value (2.0). The absolute differences in MEE were largest at the wavelengths where peak absorption 
occurs. For granular quartz and Hess/OPAC dust models, MEE were $\sim \pm 0.04 \mathrm{~m}^{2} \mathrm{~g}^{-1}$ and $\pm 0.02 \mathrm{~m}^{2} \mathrm{~g}^{-1}$ within their reference values at 9 and $10 \mu \mathrm{m}$, respectively. Hence the Hess/OPAC model is less sensitive by a factor of about 2 to changes in $\sigma_{\mathrm{g}}$, which could be related to the heterogeneity of its dust composition.

\section{Particle shape}

To illustrate the impact of particle shape on dust MEE, we again choose quartz particles with a size distribution characterized by the median VMD of $\sim 3 \mu \mathrm{m}$. In Fig. $8 \mathrm{c}$, the results for spheres, spheroids, rectangles, grains, prisms, and the two shape distributions (SD1 and SD2) are given.

Apparent are the large differences in MEE between smooth and angular particles, particularly between $8-10 \mu \mathrm{m}$. The spheres and oblate spheroids (OS), for example, exhibit large spectral peaks at 8.5 and $9 \mu \mathrm{m}$, respectively, which are not seen in the angular particles, likely due to the edge effects. As previously noted in Sect. 4.1, the Mie solutions for the quartz resonance peak at $9.2 \mu \mathrm{m}$ is blue-shifted nearly $0.5 \mu \mathrm{m}$, and is incorrectly positioned near $8.5 \mu \mathrm{m}$. The spheroids and angular particles on the other hand are much closer to the true resonance frequency of quartz.

For angular particles, the sensitivity appears to be largest in the wavelength range of 9-10.5 $\mu \mathrm{m}$, with rectangles/hexagonal prisms yielding maximum MEE. At $9 \mu \mathrm{m}$, for example, absolute differences between angular shapes approach $\sim 0.2 \mathrm{~m}^{2} \mathrm{~g}^{-1}$. At the most common remote sensing wavelengths, MEE sensitivity to shape is not as strong, but appears to be largest at $\lambda=12 \mu \mathrm{m}$.

Lastly, we evaluate MEE spectra for two dust scenarios: SD1 (background dust) and SD2 (dust storm) similar to those described in Kalashnikova et al. (2002) and are defined as: SD1 $-20 \%$ spheres $+50 \%$ angular $+30 \%$ oblate spheroids (background dust)

SD2 $-5 \%$ spheres $+75 \%$ angular $+20 \%$ oblate spheroids (dust storm)

Although dust storms may contain giant-sized particles that exceed our maximum VMD of $20 \mu \mathrm{m}$, the size range employed in this study along with the SD2 model, allow for a reasonable characterization of a dust storm's impact on MEE.

For a polydispersed SD, weighting factors are applied to the total MEE corresponding to each mineral habit. For example, in background dust, spheres are mixed with spheroids and angular particles and are weighted by the factors 0.20 , 0.30 , and 0.50 , respectively. Since the SD is a weighted mixture of the mineral habits, the resulting MEE spectra (SD1/SD2) appear to be much smoother (Fig. $8 \mathrm{c}-$ red/blue curves). Note that by adding more angular particles to the distribution, the magnitude of MEE spectra increases in the 9-12.5 $\mu \mathrm{m}$ range, whereas between $8-9 \mu \mathrm{m}$, the effects of the smooth particles dominate.

\subsection{Comparisons of MEE between the near and thermal IR}

To identify spectral relationships in the optical properties of dust between the near and thermal IR, ratios of MEE are analyzed over all possible particle compositions and sizes using spheres and spheroids. Since the Hess/OPAC and kaolinitehematite optical models are frequently applied in dust research (e.g., Huang et al., 2009; Balkanski et al., 2007; Hansell et al., 2008), we specifically focus on these compositions to help illustrate these relationships.

To this end, MEE at the near-IR wavelength of $\lambda=$ $0.870 \mu \mathrm{m}$ are compared to those at the IR wavelengths (i.e. $\lambda=3.75,8.0,8.6,9,10,11$, and $12 \mu \mathrm{m})$. Although dust optical properties exhibit a spectral dependence at the visible wavelengths (e.g., Müller et al., 2009), the properties at $\lambda=0.870 \mu \mathrm{m}$ are used as a proxy for representing wavelengths down through the green to estimate the optical properties across the visible-IR spectrum. For example, MEE derived from bulk mass and light scattering measurements at the visible wavelengths can be converted to an equivalent in the IR for use in radiation transfer and climate modeling studies. To put these comparisons into context for remote sensing purposes, the center-wavelengths of AVHRR channels 3, 4, and $5(\lambda=3.75,10.8$, and $12.0 \mu \mathrm{m}$, respectively) are used as an example.

Computed MEE ratios $\left(\alpha_{\mathrm{IR}} / \alpha_{\mathrm{NIR}}\right)$ between the near-IR $(\lambda=0.870 \mu \mathrm{m})$ and IR channels $(3.75-12 \mu \mathrm{m})$ are listed in Table 4 for spheres and oblate spheroids (OS - aspect ratio $=1.8)$ using the two prescribed dust compositions, with VMDs of $1.5,3$, and $6 \mu \mathrm{m}$. Note the AVHRR channels are listed in column 2. To better illustrate the dependence of particle size on MEE ratios, the data from Table 4 are shown plotted in Fig. 10 for spheres and oblate spheroids (aspect ratio $=1.8$ ), using the Hess/OPAC dust parameterization. The gray/black curves denote the spherical /spheroidal particle geometries, respectively, while the markers indicate the AVHRR IR channels. The mean IR/visible optical depth ratio reported by DeSouza-Machado et al. (2006) (0.425) falls within the range presented here $\left(\alpha_{\mathrm{IR}} / \alpha_{\mathrm{NIR}}=0.3-0.7\right)$ assuming a Hess/OPAC spherical dust model for the commonly observed VMDs of 3-6 $\mu \mathrm{m}$ at $\lambda=10.8 \mu \mathrm{m}$ (channel 4).

Apparent is the rapid increase and convergence $\left(\alpha_{\mathrm{IR}} / \alpha_{\mathrm{NIR}}=1\right.$; broken black line $)$ of the MEE ratios for both shapes as particle VMD increases, an effect attributed to the changing particle size parameter (i.e., $\alpha_{\mathrm{NIR}}>\alpha_{\mathrm{IR}}$ for small particles, and $\alpha_{\mathrm{IR}}>\alpha_{\mathrm{NIR}}$ for large particles). Depending on particle size, the ratios display a shape dependency, where spheroids tend to have a greater impact (i.e., larger MEE) at visible wavelengths $\left(\alpha_{\mathrm{NIR}} / \alpha_{\mathrm{IR}} \geq 1\right)$ than do spheres for particle sizes with VMDs $\leq \sim 9 \mu \mathrm{m}$. For larger particles (VMDs $>\sim 9 \mu \mathrm{m}$ ) however, $\alpha_{\mathrm{NIR}} / \alpha_{\mathrm{IR}} \leq 1$ and the MEE ratios are nearly insensitive to shape. The magnitude of the ratio effectively tracks the relative significance of dust extinctive properties between the visible and IR wavelengths. 
Table 4. MEE ratios $\left(\alpha_{\mathrm{IR}} / \alpha_{\mathrm{NIR}}\right)$ - from the near to thermal IR.

\begin{tabular}{|c|c|c|c|c|c|c|c|}
\hline \multirow[t]{3}{*}{ Shape } & \multirow{3}{*}{$\begin{array}{r}\text { Wavelength/Channel } \\
\qquad \lambda(\mu \mathrm{m})\end{array}$} & \multicolumn{3}{|c|}{$\begin{array}{l}\text { Kaolinite-hematite } \\
\text { mixture }\end{array}$} & \multicolumn{3}{|c|}{$\begin{array}{c}\text { OPAC/Hess } \\
\text { Parameterization }^{\mathrm{a}}\end{array}$} \\
\hline & & \multicolumn{3}{|c|}{$\operatorname{VMD}(\mu \mathrm{m})$} & \multicolumn{3}{|c|}{$\operatorname{VMD}(\mu \mathrm{m})$} \\
\hline & & 1.5 & 3 & 6 & 1.5 & 3 & 6 \\
\hline \multirow{11}{*}{ Sphere } & $3.75 /(3)$ & 0.48 & 0.83 & 1.11 & 0.17 & 0.59 & 1.00 \\
\hline & 8.0 & 0.03 & 0.05 & 0.11 & 0.05 & 0.12 & 0.25 \\
\hline & 8.6 & 0.09 & 0.14 & 0.22 & 0.09 & 0.22 & 0.37 \\
\hline & 9.0 & 0.40 & 0.50 & 0.63 & 0.15 & 0.45 & 0.83 \\
\hline & 10.0 & 0.38 & 0.77 & 1.11 & 0.15 & 0.53 & 1.00 \\
\hline & $10.8 /(4)$ & 0.31 & 0.63 & 1.00 & 0.08 & 0.33 & 0.71 \\
\hline & 11.0 & 0.29 & 0.63 & 1.00 & 0.07 & 0.28 & 0.63 \\
\hline & $12.0 /(5)$ & 0.05 & 0.19 & 0.43 & 0.10 & 0.31 & 0.63 \\
\hline & $3.75 /(3)$ & 0.03 & 0.14 & 0.33 & 0.04 & 0.14 & 0.32 \\
\hline & 8.0 & 0.01 & 0.01 & 0.02 & 0.03 & 0.04 & 0.07 \\
\hline & 8.6 & 0.02 & 0.04 & 0.06 & 0.07 & 0.09 & 0.14 \\
\hline Spheroid & 9.0 & 0.13 & 0.17 & 0.25 & 0.08 & 0.14 & 0.27 \\
\hline \multirow[t]{4}{*}{ (OS 1.8) } & 10.0 & 0.05 & 0.14 & 0.31 & 0.06 & 0.14 & 0.31 \\
\hline & $10.8 /(4)$ & 0.05 & 0.11 & 0.26 & 0.04 & 0.08 & 0.17 \\
\hline & 11.0 & 0.05 & 0.11 & 0.24 & 0.03 & 0.06 & 0.14 \\
\hline & $12.0 /(5)$ & 0.01 & 0.02 & 0.05 & 0.06 & 0.09 & 0.18 \\
\hline
\end{tabular}

Note: AVHRR channels 3, 4 and 5 are listed in column 2.

${ }^{a}$ See Fig. 10 for plot of OPAC/Hess MEE ratios using spheres and spheroids.

\subsection{Discussion}

The efficacy of this study can be demonstrated with a simple example. Suppose the research objective is to estimate optical properties in the IR to approximate dust impacts on AVHRR SST retrievals. Note this example can also be applied to approximating dust impacts on retrievals of other key land or atmospheric parameters. For simplicity, we assume dust particles are spherical and that MEE at $0.55 \mu \mathrm{m}$ can be derived from bulk mass and light scattering/absorption measurements. Following J. S. Reid et al. (2003), an average MEE of $\sim 0.65 \mathrm{~m}^{2} \mathrm{~g}^{-1}$ at $0.55 \mu \mathrm{m}$ is implied for Saharan dust after adding the contributions from scattering $\left(0.5 \pm 0.1 \mathrm{~m}^{2} \mathrm{~g}^{-1}\right.$, Maring et al., 2000) and absorption $\left(0.08 \mathrm{~m}^{2} \mathrm{~g}^{-1}\right.$, personal communications with D. Savoie, 2001). Applying the Hess/OPAC dust model for a particle VMD of $3.0 \mu \mathrm{m}$ (Table 4), the corresponding MEE at $3.75,10.8$, and $12.0 \mu \mathrm{m}$ are estimated to be $\sim 0.4,0.21$, and $0.20 \mathrm{~m}^{2} \mathrm{~g}^{-1}$, respectively. The MEE in turn translates into a dust IR aerosol optical depth (AOT) of around $\tau=0.4,0.21$, and 0.20 at the three wavelengths, respectively, assuming a column dust load of $1 \mathrm{~g} \mathrm{~m}^{-2}$. Incidentally, the visible AOT $(0.55 \mu \mathrm{m})$ is $\tau=0.65$. Using the estimated channel AOTs and accounting for the atmospheric state, surface properties and dust distribution in a radiative transfer model, the dust effect can be calculated by the difference in brightness temperature (BT) between channels 4 and 5 (i.e., BT4-BT5) of the AVHRR with and without dust. If, for example, the dust top/bottom is $2.0 / 0.5 \mathrm{~km}$, respectively $(\Delta z=1.5 \mathrm{~km})$, in an atmosphere characterized by a mid-latitude summer profile, the SST will be negatively biased by $\sim{ }^{\circ} \mathrm{C}$.

Other potential benefits of extending field derived MEE at the visible wavelengths to the IR include: (1) characterizing the thermal impacts of dust aerosol during retrievals of water vapor using AIRS spectral data, for example, where biases due to atmospheric dust can be important in applications such as weather-forecasting and (2) estimating regional longwave DARE over the column atmosphere to help facilitate a better understanding of ensuing surface-air exchange processes and ultimately the general circulation of the atmosphere.

The upper and lower bounds of the MEE spectral envelope computed in this study are aimed at providing a range of plausible values covering an extended array of dust microphysical and chemistry perturbations. Further constraints in key aerosol measurements (e.g., particle size, composition, etc.), will continue to advance our knowledge of dust MEE data from the near to thermal IR. 


\section{Summary}

Sensitivity analyses were performed over an extended range of dust microphysical and chemistry perturbations, to determine a plausible range of MEE for terrestrial atmospheric dust, at wavelengths commonly used in remote sensing spanning the near to thermal IR. Over the parameterizations investigated, the upper and lower bounds of the MEE spectral envelope were found. For reference, MEE spectra based on field and laboratory data were also computed. The following major conclusions were noted:

- In the frequently observed dust size range $(\mathrm{VMD}=3-$ $6 \mu \mathrm{m})$, two dominant peaks were identified: one at $\lambda=0.870 \mu \mathrm{m}$ and the other at $\lambda=9 \mu \mathrm{m}$, with maximum MEE values reaching nearly $\alpha_{\text {ext }}=0.90$ and $0.80, \mathrm{~m}^{2} \mathrm{~g}^{-1}$, respectively. Both maxima were attributed to non-spherical particles with the near-IR peak composed primarily of gypsum, clay minerals and the clay-hematite mixture. The second peak was mostly attributed to quartz due to the strong $\mathrm{Si}-\mathrm{O}$ stretch resonance at $9.2 \mu \mathrm{m}$.

- Mie spherical MEE solutions for quartz spheres in the thermal IR are blue-shifted by $\sim 0.5 \mu \mathrm{m}$ compared with spheroids and angular particles. As shown in previous studies, spherical particles are not able to accurately reproduce the resonance peaks commonly found in silicate minerals.

- The shapes in MEE spectral distributions appear to follow particle geometry, particularly for oblate spheroids. This provides more evidence for shape dependency in the optical properties of mineral dust.

- Generally, angular particles have wider and more symmetric MEE spectral distributions from $8-10 \mu \mathrm{m}$ than those with smooth surfaces, likely due to their edgeeffects.

- At shorter wavelengths $(\lambda=0.87 \mu \mathrm{m})$, MEE tends to increase when going from spherical to non-spherical particles. Single particle MEE for several angular geometries was found to be about 2-3 times greater than that of spheres. Increases in MEE at short wavelengths are primarily due to enhancements in scattering (MSE), when MAE tends to zero.

- In the thermal IR, changes in MEE due to particle shape strongly depend on VMD and wavelength, particularly if MEE is evaluated at the mineral resonant frequencies where MEE and MAE generally tend to increase when going from spheres to non-spheres; however, outside of these strongly absorbing regions, MEE and MAE tend to decrease.

This study not only bounds the MEE of dust aerosols over the parameter space examined, but it also provides a mechanism for linking the spectral optical properties of dust between the visible and IR wavelengths. Potential applications for the derived MEE data include remote sensing of atmospheric and surface parameters (e.g., SST and water vapor), computing LW energetics and DARE, and providing a reference for field derived MEE. Further constraints in key aerosol measurements (e.g., particle size, composition, etc.), will continue to advance our knowledge of dust MEE from the near to thermal IR.

\section{List of key acronyms and symbols}

\begin{tabular}{ll}
\hline ACE-Asia & Aerosol Characterization Experiment-Asia \\
AMMA & African Monsoon Multidisciplinary Analyses \\
DABEX & Dust and Biomass Burning Experiment (during AMMA) \\
DARE & Direct aerosol radiative effect \\
MAE & Mass absorption efficiency \\
MEE & Mass extinction efficiency \\
MSE & Mass scattering efficiency \\
NAMMA & NASA African Monsoon Multidisciplinary Analyses \\
OPAC & Optical properties of aerosols and clouds \\
PRIDE & Puerto Rican Dust Experiment \\
SAMUM & Saharan Mineral Dust Experiment \\
SHADE & Saharan Dust Experiment \\
SOP0 & Special Observing Period 0 (during AMMA) \\
UAE & United Arab Emirates Unified Aerosol Experiment \\
VMD & Volume median diameter \\
$\alpha_{\mathrm{sp}}$ & Single particle mass extinction efficiency \\
$\alpha_{\mathrm{ext}}$ & Mass extinction efficiency \\
$k$ & Imaginary component of refractive index \\
$\alpha^{\prime}$ & Absorption coefficient \\
$v_{2}$ & Fundamental asymmetric stretching vibration \\
$v$ & Wavenumber (cm \\
$\beta_{\mathrm{e}}$ & Extinction coefficient \\
$\mathrm{Q}_{\mathrm{e}}$ & Optical extinction efficiency \\
$\sigma_{\mathrm{e}}$ & Extinction cross section \\
$m$ & Complex refractive index \\
$k^{\prime}$ & Free-space wave number \\
\hline &
\end{tabular}

\section{Supplementary material related to this article is available online at: http://www.atmos-chem-phys.net/11/1527/2011/ acp-11-1527-2011-supplement.pdf.}

Acknowledgements. We are grateful to B. Draine and P. Flatau, and M. Mishchenko for making the DDA, and T-matrix and Lorenz-Mie light scattering codes available, respectively. We also acknowledge those who maintain the websites (http://webmineral.com and http://mindat.org) and for making the mineral data publicly available. We thank Ralph Kahn for his review and comments to this paper, and lastly, we thank the anonymous referees for their insightful comments and suggestions. Funding for this research was provided by the NASA Radiation Science Program and Office of Naval Research Code 32\&35.

Edited by: A. Petzold 


\section{References}

Arbelo, M., Hernandez-Leal, P. A., Perez-Garcia, S., and GonzalezCalvo, A.: SeaWIFS data to detect AVHRR-derived SST affected by aerosols, Adv. Space Res., 36, 783-786, 2005.

Arimoto, R. Y. J., Kim, Y. J., Kim, Y. P., Quinn, P. K., Bates, T. S., Anderson, T. L., Gong, S., Uno, I., Chin, M., Huebert, B. J., Clarke, A. D., Shinozuka, Y., Weber, R. J., Anderson, J. R., Guazzotti, S. A., Sullivan, R. C., Sodeman, D. A., Prather, K. A., and Sokolik, I. N.: Characterization of Asian dust during ACEAsia, global and Planetary, 52, 23-56, 2006.

Aronson, J. R. and Strong, P. F.: Optical constants of minerals and rocks, Appl. Optics, 14, 2914-2920, 1975.

Balkanski, Y., Schulz, M., Claquin, T., and Guibert, S.: Reevaluation of Mineral aerosol radiative forcings suggests a better agreement with satellite and AERONET data, Atmos. Chem. Phys., 7, 81-95, doi:10.5194/acp-7-81-2007, 2007.

Clarke, A. D., Shinozuka, Y., Kapustin, V. N., Howell, S., Huebert, B., Doherty, S., Anderson, T., Covert, D., Anderson, J., Hua, X., Moore II, K. G., McNaughton, C., Carmichael, G., and Weber, R.: Size distributions and mixtures of dust and black carbon aerosol in Asian outflow: Physiochemistry and optical properties, J. Geophys. Res., 109, D15S09, doi:1029/2003JD004, 2004.

Chou, C., Formenti, P., Maille, M., Ausset, P., Helas, G., Harrison, M., and Osborne, S.: Size distribution, shape, and composition of mineral dust aerosols collected during the African Monsoon Multidisciplinary Analysis Special Observation Period 0: Dust and Biomass-Burning Experiment field campaign in Niger, January 2006, J. Geophys. Res., 113, D00C10, doi:10.1029/2008JD009897, 2008.

D'Almeida, G. A., Koepke, P., and Shettle, E. P.: Atmospheric aerosols: global climatology and radiative characteristics. A. Deepak Publishing, Hampton, Virginia, USA, 561 pp., 1991.

DeSouza-Machado, S. G., Strow, L. L., Hannon, S. E., and Motteler, H. E.: Infrared dust spectral signatures from AIRS, Geophys. Res. Lett., 33, L03801, doi:10.1029/2005GL024364, 2006.

Draine, B. T.: The Discrete-Dipole Approximation for Light Scattering by Irregular Targets, in: Light Scattering by Nonspherical Particles: Theory, Measurements, and Geophysical Applications, edited by: Mishchenko, M. I., Hovenier, J. W., and Travis , L. D., (N.Y.: Academic Press), 133-145, 2000.

Draine, B. T. and Flatau, P. J.: User Guide to the Discrete Dipole Approximation Code DDSCAT 6.1, available at: http://arxiv.org/ abs/astro-ph/0409262v2, 2004.

Draine, B. T. and Weingartner, J.C.: Radiative Torques on Interstellar Grains, I. Superthermal Spin-Up, ApJ, 470, 551-565, 1996.

Drummond, D. G.: The Infra-Red Absorption Spectra of Quartz and Fused Silica from 1 to 7.5 Microns, Proc. R. Soc. London Ser. A 153, 328, 1935.

Egan, W. G. and Hilgeman, T. W.: Optical Properties of Inhomogeneous Materials: Applications to Geology, Astronomy, Chemistry, and Engineering, Academic Press, 1979.

Farmer, V. C.: The Infrared Spectra of Minerals, Mineralogical Society, London, 1974.

Formenti, P., Elbert, W., Maenhaut, W., Haywood, J., and Andreae, M. O.: Chemical composition of mineral dust aerosol during the Saharan Dust Experiment (SHADE) airborne campaign in the Cape Verde region, September 2000, J. Geophys. Res., 108(D18), 8576, doi:10.1029/2002JD002648, 2003.

Formenti, P., Rajot, J. L., Desboeufs, K., Caquineau, S., Chevail- lier, S., Nava, S., Gaudichet, A., Journet, E., Triquet, S., Alfaro, S., Chiari, M., Haywood, J., Coe, H., and Highwood, E.: Regional variability of the composition of mineral dust from western Africa: Results from the AMMA SOP0/DABEX and DODO field campaigns, J. Geophys. Res., 113, D00C13, doi:10.1029/2008JD009903, 2008.

Gerasopoulos, E., Kokkalis, P., Amiridis, V., Liakakou, E., Perez, C., Haustein, K., Eleftheratos, K., Andreae, M. O., Andreae, T. W., and Zerefos, C. S.: Dust specific extinction cross-sections over the Eastern Mediterranean using the BSC-DREAM model and sun photometer data: the case of urban environments, Ann. Geophys., 27, 2903-2912, doi:10.5194/angeo-27-29032009, 2009.

Glotch, T. M., Rossman, G. R., and Aharonson, O.: Mid-infrared $(5-100 \mu \mathrm{m})$ reflectance spectra and optical constants of ten phyllosilicate minerals, Icarus, 192, 605-622, 2007.

Gray, E. D.: American Institute of Physics Handbook, 2nd edn (New York: McGraw-Hill), 4-285, 1963.

Griffen, D. T.: Silicate Crystal Chemistry, Oxford University Press, 442 pp., 1992.

Hand, J. L. and Malm, W. C.: Review of aerosol mass scattering efficiencies from ground-based measurements since 1990, J. Geophys. Res., 112, D16203, doi:10.1029/2007JD008484, 2007.

Hand, J. L., Kreidenweis, S. M., Sherman, D. E., Collett Jr., J. L., Hering, S. V., Day, D. E., and Malm, W. C.: Aerosol size distributions and visibility estimates during the Big Bend Regional Aerosol Visibility and Observational Study (BRAVO), Atmos. Environ., 36, 5043-5055, 2002.

Hansell, R. A., Liou, K. N., Ou, S. C., Tsay, S. C., Ji, Q., and Reid, J. S: Remote sensing of mineral dust aerosol using AERI during the UAE2: A modeling and sensitivity study, J. Geophys. Res., 113, D18202, doi:10.1029/2008JD010246, 2008.

Hansell, R. A., Tsay, S. C., Ji, Q., Hsu, N. C., Jeong, M. J., Wang, S. H., Reid, J. S., Liou, K. N., and Ou, S. C: An Assessment of the Surface Longwave Direct Radiative Effect of Airborne Saharan Dust during the NAMMA Field Campaign, J. Atmos. Sci., 67, 1048-1065, 2010.

Haywood, J. M., Pelon, J., Formenti, P., Bharmal, N., Brooks, M., Capes, G., Chazette, P., Chou, C., Christopher, S., Coe, H., Cuesta, J., Derimian, Y., Desboeufs, K., Greed, G., Harrison, M., Heese, B., Highwood, E.J., Johnson, B., Mallet, M., Marticorena, B., Marsham, J., Milton, S., Myhre, G., Osborne, S. R., Parker, D. J., Rajot, J.-L., M. Shulz, M., Slingo, A., Tanre, D., and Tulet, P.: Overview of the Dust and Biomass-burning Experiment and African Monsoon Multidisciplinary Analysis Special Observing Period-0, J. Geophys. Res., 113, D00C17, doi:10.1029/2008JD010077, 2008.

Hess, M., Koepke, P., and Schult, I.: Optical Properties of Aerosols and Clouds: The Software Package OPAC, BAMS, 1998.

Holben, H. B., Eck, T. F., Slutsker, I., Tanr, D., Buis, J. P., Setzer, A., Vermote, E., Reagan, J. A., Kaufman, Y. J., Nakajima, T., Lavenu, F., Jankowiak, I., and Smirnov, A.: AERONET -A federated instrument network and data archive for aerosol characterisation, Remote Sens. Environ., 66, 1-16, 1998.

Huang, J., Fu, Q., Su, J., Tang, Q., Minnis, P., Hu, Y., Yi, Y., and Zhao, Q.: Taklimakan dust aerosol radiative heating derived from CALIPSO observations using the Fu-Liou radiation model with CERES constraints, Atmos. Chem. Phys., 9, 4011-4021, doi:10.5194/acp-9-4011-2009, 2009. 
Hudson, P. K., Gibson, E. R., Young, M. A., Kleiber, P. D., and Grassian, V. H., Coupled infrared extinction and size distribution measurements for several clay components of mineral dust aerosol, J. Geophys. Res., 113, D01201, doi:10.1029/2007JD008791, 2008.

Huggins, M. L.: The Crystal Structure of Quartz, Phys. Rev. 19, 363-368, 1922.

Jeong, G. Y.: Bulk and single-particle mineralogy of Asian dust and a comparison with its source soils, J. Geophys. Res., 113, D02208, doi:10.1029/2007JD008606, 2008.

Kahn, R. A., Garay, M. J., Nelson, D. L., Yau, K. K., Bull, M. A., Gaitley, B. J., Martonchik, J. V., and Levy, R. C.: Satellite-derived aerosol optical depth over dark water from MISR and MODIS: Comparisons with AERONET and implications for climatological studies, J. Geophys. Res., 112, D18205, doi:10.1029/2006JD008175, 2007.

Kahn, R. A., Petzold, A., Wendisch, M., Bierwirth, E., Dinter, T., Esselborn, M., Fiebig, M., Heese, B., Knippertz, P., Müller, D., Schladitz, A., and Hoyningen-Huene, W. V.: Desert dust aerosol air mass mapping in the western Sahara, using particle properties derived from space-based multi-angle imaging, Tellus B, 61, 239-251, 2009.

Kalashnikova, O. V. and Sokolik, I. N.: Importance of shapes and compositions of wind-blown dust particles for remote sensing at solar wavelengths, Geophys. Res. Lett., 29(10), 1398, doi:10.1029/2002GL014947, 2002.

Kalashnikova, O. V. and Sokolik, I. N.: Modeling the radiative properties of non-spherical soil-derived mineral aerosols, J. Quant. Spectrosc. Ra., 87, 137-166, 2004.

Kalashnikova, O. V., Kahn, R., Sokolik, I. N., and Li, W.-H.: Ability of multiangle remote sensing observations to identify and distinguish mineral dust types: optical models and retrievals of optically thick plumes, J. Geophys. Res., 110, D18519, doi:10.1029/2004JD004550, 2005.

Kandler, K., Schutz, L., Deutscher, C., Ebert, M., Hofmann, H., Jackel, S., Jaenicke, R., Knippertz, P., Lieke, K., Massling, A., Petzold, A., Schladitz, A., Weinzierl, B., Wiedensohler, A., Zorn, S., and Weinbruch, S.: Size distribution, mass concentration, chemical and mineralogical composition, and derived optical parameters of the boundary layer aerosol at Tinfou, Morocco, during SAMUM, 2006, Tellus B, 61, 32-50, 2009.

Karr, C.: Infrared and Raman Spectroscopy of Lunar and Terrestrial Minerals, Academic Press, Inc., 375 pp., 1975.

Kerr, P. F.: Optical Mineralogy, McGraw-Hill Book Company, Inc., 442 pp., 1959.

Koepke, P., Hess, M., Schult, I., and Shettle, E. P.: Global Aerosol Data Set, Report No. 243, Max-Planck-Institut für Meteorologie, Hamburg, ISSN:0937-1060, 1997.

Lafon, S., Sokolik, I. N., Rajot, J. L., Caquineau, S., and Gaudichet, A.: Characterization of iron oxides in mineral dust aerosols: Implications for light absorption, J. Geophys. Res., 111, D21207, doi:10.1029/2005JD007016, 2006.

Lazaro, F. J., Gutierrez, L., Barron, V., and Gelado, M. D.: The speciation of iron in desert dust collected in Gran Canaria (Canary Islands): Combined chemical, magnetic and optical analysis, Atmos. Environ., 42, 8987-8996, 2008.

Levy, R. C., Remer, L. A., and Dubovik, O.: Global aerosol optical properties and application to MODIS aerosol retrieval over land, J. Geophys. Res., 112, D13210, doi:10.1029/2006JD007815,
2007.

Li., X., Maring, H., Savoie, D., Voss, K., and Prospero, J. M.: Dominance of mineral dust in aerosol light-scattering in the North Atlantic trade winds, Nature, 380, 416-419 doi:10.1038/380416a0, 1996.

Linke, C., Möhler, O., Veres, A., Mohácsi, Á., Bozóki, Z., Szabó, G., and Schnaiter, M.: Optical properties and mineralogical composition of different Saharan mineral dust samples: a laboratory study, Atmos. Chem. Phys., 6, 3315-3323, doi:10.5194/acp-63315-2006, 2006.

Long, L. L., Querry, M. R., Bell, R. J., and Alexander, R. W.: Optical properties of calcite and gypsum in crystalline and powdered form in the infrared and far-infrared, Infrared Phys., 34(2), 191201, 1993.

Longtin, D. R.: A Wind Dependent Desert Aerosol Model: Radiative Properties, Air Force Geophysics Laboratory, AFL-TR-880122, 1988.

Malm, W. C., Day, D. E., Carrico, C., Kreidenweis, S. M., Collett Jr., J. L., McMeeking, G., Lee, T., Carillo, J., and Schichtel, B.: Intercomparison and closure calculations using measurements of aerosol species and optical properties during the Yosemite Aerosol Characterization Study, J. Geophys. Res., 110, D14302, doi:10.1029/2004JD005494, 2005.

Manghnani, M. H. and Hower, J.: Glauconites: Cation Exchange Capacities and Infrared Spectra Part II. Infrared Absorption Characteristics of Glauconites, Am. Mineral, 49, 1631-1642, 1964.

Maring, H., Savoie, D., Izaguirre, M., McCormick, C., Arimoto, R., Prospero, J., and Pilinis, C.: Aerosol physical and optical properties and their relationship to aerosol composition in the free troposphere at Izaña, Tenerife, Canary Islands, during July 1995, J. Geophys. Res., 105(D11), 14677-14700, 2000.

Mishchenko, M. I. and Travis, L. D: Light scattering by polydispersions of randomly oriented spheroids with sizes comparable to wavelengths of observation. Appl. Optics, 33, 7206-7225, 1994.

Mishchenko, M. I. and Travis, L. D.: Capabilities and limitations of a current fortran implementation of the T-Matrix method for randomly oriented, rotationally symmetric scatterers, J. Quant. Spectrosc. Ra., 60, 309-324, 1998.

Mooney, T. and Knacke, R. F.: Optical Constants of Chlorite and Serpentine between 2.5 and $50 \mu \mathrm{m}$, Icarus, 64, 493-502, 1985.

Müller, T., Schladitz, A., Massling, A., Kaaden, N., Kandler, K., and Wiedensohler, A.: Spectral absorption coefficients and imaginary parts of refractive indices of Saharan dust during SAMUM1, Tellus B, 61, 79-95, 2009.

Müller, D., Ansmann, A., Freudenthaler, V., Kandler, K., Toledano, C., Hiebsch, A., Gasteiger, J., Esselborn, M., Tesche, M., Heese, B., Althausen, D., Weinzierl, B., Petzold, A., and von Hoyningen-Huene, W.: Mineral dust observed with AERONET Sun photometer, Raman lidar, and in situ instruments during SAMUM 2006: Shape-dependent particle properties, J. Geophys. Res., 115, D11207, doi:10.1029/2009JD012523, 2010.

Myhre, G. and Stordal, F.: Global sensitivity experiments of the radiative forcing due to mineral aerosols, J. Geophys. Res., 106(D16), 18193-18204, 2001.

Nousiainen, T.: Optical modeling of mineral dust particles: A review, J. Quant. Spectrosc. Ra., 110, 1261-1279, 2009a.

Nousiainen, T., Zubko, E., Niemi, J. V., Kupiainen, K., Lehtinen, M., Muinonen, K., and Videen, G.: Single-scattering mod- 
eling of thin, birefringent mineral-dust flakes using the discrete dipole approximation, J. Geophys. Res., 114, D07207, doi:10.1029/2008JD011564, 2009b.

Okada, K., Heitzenberg, J., Kai, K., and Qin, Y.: Shape of atmospheric mineral particles collected in 3 Chinese arid regions, Geophys. Res. Lett., 28, 3123-3126, 2001.

Otto, S., Bierwirth, E., Weinzierl, B., Kandler, K., Esselborn, M., Tesche, M., Schladitz, A., Wendisch, M., and Trautmann, T.: Solar radiative effects of a Saharan dust plume observed during SAMUM assuming spheroidal model particles Tellus B, 61, 270296, 2009.

Philipp, H. R.: Silicon dioxide $\left(\mathrm{SiO}_{2}\right)$, type $\alpha$ (Crystalline), in: Handbook of Optical Constants of Solids, edited by: Palik, E. D., Academic, p. 719, 1985 .

Quinn, P. K., Coffman, D. J., Bates, T. S., Welton, E. J., Covert, D. S., Miller, T. L., Johnson, J. E., Maria, S., Russell, L., Arimoto Carrico, C. M., Rood, M. J., and Anderson, J.: Aerosol optical properties measured on board the Ronald H. Brown during ACE-ASIA as a function of aerosol chemical composition and source region, J. Geophys. Res., 109, D19S01, doi:10.1029/2003JD004010, 2004.

Redelsperger, J. L., Thorncroft, C. D., Diedhiou, A., Lebel, T., Parker, D. J., and Polcher, J.: African Monsoon Multidisciplinary Analysis: An international research project and field campaign, B. Am. Meteorol. Soc., 87, 1739-1746, doi:10.1175/BAMS-8712-1739, 2006.

Reid, E. A., Reid, J. S., Meier, M. M., Dunlap, M. R., Cliff, S. S., Broumas, A., Perry, K., and Maring, H.: Characterization of African dust transported to Puerto Rico by individual particle and size segregated bulk analysis, J. Geophys. Res., 108(D19), 8591, doi:10.1029/2002JD002935, 2003.

Reid, J. S., Jonsson, H. H., Maring, H. B., Smirnov, A., Savoie, D. L., Cliff, S. S., Reid, E. A., Livingston, J. M., Meier, M. M., Dubovik, O., and Tsay, S. C.: Comparison of size and morphological measurements of coarse mode dust particles from Africa, J. Geophys. Res., 108(D19), 8593, doi:10.1029/2002JD002485, 2003.

Reid, J. S., Reid E. A., Walker, A., Piketh, S., Cliff, S., Al Mandoos, A., Tsay, S. C., and Eck, T. F.: Dynamics of Southwest Asian Dust Particle Size Characteristics with Implications for Global Dust Research, J. Geophys Res., 113, D14212, doi:10.1029/2007JD009752, 2008.

Querry, M. R.: Optical Constants of Minerals and other Materials from the Millimeter to the Ultraviolet, CRDEC-CR88009, Chemical Research, Development and Engineering Center, Aberdeen Proving Ground, MD, 331 pp., 1987.

Roush, T. L.: Near-infrared $(0.67-4.7 \mu \mathrm{m})$ optical constants estimated for montmorillonite, Icarus, 179, 259-264, 2005.
Roush, T. L., Pollack, J., and Orenberg, J.: Derivation of midinfrared $(5-25 \mu \mathrm{m})$ optical constants of some silicates and palagonite, Icarus, 94, 191-208, 1991.

Roush, T. L., Esposito, F., Rossman, G. R., and Colangeli, L.: Estimated optical constants of gypsum in the regions of weak absorptions: Application of scattering theories and comparisons to independent measurements, J. Geophys. Res., 112, E10003, doi:10.1029/2007JE002920, 2007.

Salisbury, J. W. and Vergo, N.: Infrared (2.1-25 $\mu \mathrm{m})$ spectra of minerals, John Hopkins University Press, p. 267, 1991.

Schladitz, A., Müller, T., Kaaden, N., Massling, A., Kandler, K., Ebert, M., Weinbruch, S., Deutscher, C., and Wiedensohler, A. : In situ measurements of optical properties at Tinfou (Morocco) during the Saharan Mineral Dust Experiment SAMUM 2006, Tellus B, 61, 64-78, 2009.

Seinfeld, J. H. and Pandis, S. N.: Atmospheric Chemistry and Physics, From Air Pollution to Climate Change, John Wiley \& Sons, Inc, 1998.

Shettle, E. P. and Fenn, R. W.: Models for the Aerosols for the Lower Atmosphere and the Effects of Humidity Variations on Their Optical Properties. AFGL-TR-79-0214 Environmental Research Papers No. 676, 1979.

Spitzer, W. G. and Kleinman, D. A.: Infrared Lattice Bands of Quartz, Phys. Rev., 121, 1324-1335, 1961.

Sokolik, I. N. and Toon, O. B.: Incorporation of mineralogical composition into models of the radiative properties of mineral aerosols from UV to IR wavelengths, J. Geophys. Res., 104, 9423-9444, 1999.

Volz, F. E.: Infrared optical constants of ammonium sulfate, Sahara dust, volcanic pumice, and flyash, Appl. Optics, 12, 564-568, 1973.

Weinzierl, B., Petzold, A., Esselborn, M., Wirth, M., Rasp, K., Kandler, K., Schütz, L., Koepke, P., and Fiebig, M.: Airborne measurements of dust layer properties, particle size distribution and mixing state of Saharan dust during SAMUM 2006, Tellus B, 61, 96-117, 2009.

Yang, P. and Liou, K. N.: Light scattering by hexagonal ice crystals: comparison of finite difference time domain and geometric optics models, J. Opt. Soc. Am., 12, 162-176, 1995.

Zipser, E. J., Twohy, C. H., Tsay, S. C., Thornhill, K. L., Tanelli, S., Ross, R., Krishnamurti, T. N., Ji, Q., Jenkins, G., Ismail, S., Hsu, N. C., Hood, R., Heymsfield, G. M., Halverson, J., Goodman, H. M., Ferrare, R., Dunion, J. P., Douglas, M., Cifelli, R., Chen, G., Browell, E. V., and Anderson, B.: The Saharan Air Layer and the Fate of African Easterly Waves, NASA's AMMA Field Study of Tropical Cyclogenesis, B. Am. Meteorol. Soc., 90, 1137-115, 2009. 